\title{
"Last-Mile" preparation for a potential disaster - Interdisciplinary approach towards tsunami early warning and an evacuation information system for the coastal city of Padang, Indonesia
}

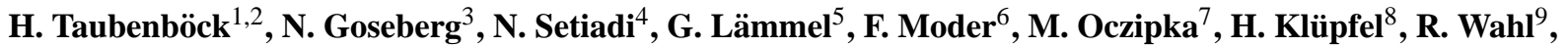 \\ T. Schlurmann ${ }^{3}$, G. Strunz ${ }^{1}$, J. Birkmann ${ }^{4}$, K. Nagel ${ }^{5}$, F. Siegert ${ }^{6}$, F. Lehmann ${ }^{7}$, S. Dech ${ }^{1,2}$, A. Gress ${ }^{9}$, and R. Klein ${ }^{9}$ \\ ${ }^{1}$ German Remote Sensing Data Center (DFD), German Aerospace Center (DLR), 82234 Oberpfaffenhofen, Germany \\ ${ }^{2}$ Julius-Maximilians University Würzburg, Geographical Institute, Earth Observation, 97074 Würzburg, Germany \\ ${ }^{3}$ Leibniz University Hannover, Franzius-Institut für Wasserbau und Küsteningenieurwesen, 30167 Hannover, Germany \\ ${ }^{4}$ United Nations University, Institute for Environment and Human Security (UNU-EHS), 53113 Bonn, Germany \\ ${ }^{5}$ Technical University Berlin, Verkehrssystemplanung und Verkehrstelematik, Institut für Land- und Seeverkehr, \\ Fakultät V - Verkehr- und Maschinensysteme, 10587 Berlin, Germany \\ ${ }^{6}$ Remote Sensing Solutions GmbH (RSS), 81667 München, Germany \\ ${ }^{7}$ Institut für Robotik und Mechatronik, German Aerospace Center (DLR), Berlin-Adlershof, Germany \\ ${ }^{8}$ TraffGo HT GmbH, Falkstr. 73-77, 47058 Duisburg, Germany \\ ${ }^{9}$ Insitute of Computer Science II, University of Bonn, 53117 Bonn, Germany
}

Received: 4 May 2009 - Revised: 24 July 2009 - Accepted: 6 August 2009 - Published: 28 August 2009

\begin{abstract}
Extreme natural events, like e.g. tsunamis or earthquakes, regularly lead to catastrophes with dramatic consequences. In recent years natural disasters caused hundreds of thousands of deaths, destruction of infrastructure, disruption of economic activity and loss of billions of dollars worth of property and thus revealed considerable deficits hindering their effective management: Needs for stakeholders, decision-makers as well as for persons concerned include systematic risk identification and evaluation, a way to assess countermeasures, awareness raising and decision support systems to be employed before, during and after crisis situations. The overall goal of this study focuses on interdisciplinary integration of various scientific disciplines to contribute to a tsunami early warning information system. In comparison to most studies our focus is on high-end geometric and thematic analysis to meet the requirements of smallscale, heterogeneous and complex coastal urban systems. Data, methods and results from engineering, remote sensing and social sciences are interlinked and provide comprehensive information for disaster risk assessment, management and reduction. In detail, we combine inundation modeling, urban morphology analysis, population assessment, socio-
\end{abstract}

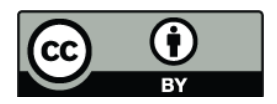

Correspondence to: $\mathrm{H}$. Taubenböck (hannes.taubenboeck@dlr.de) economic analysis of the population and evacuation modeling. The interdisciplinary results eventually lead to recommendations for mitigation strategies in the fields of spatial planning or coping capacity.

\section{Introduction}

Tsunamis are an ever-present threat to lives, infrastructure, and property along the coasts of the world's oceans. Indonesia has recently been struck by a series of major earthquakes and arising tsunamis that have largely affected cities: the 2004 tsunami and earthquakes (devastating the cities of Banda Aceh and Meulaboh) and the 2006 central Java earthquake (impacting the Yogyakarta region) with an ensuing tsunami (Leitmann, 2007). The dimension of the 2004 tsunami disaster claiming nearly 275000 lives and destroying billions of dollars' worth of property (Barber, 2005) reminded the world, to be more proactive in developing ways to reduce their impact.

Today, several end-to-end tsunami early warning systems are operated. Examples are the US National Tsunami Hazard Mitigation System (NTHMP) in the eastern Pacific (Bernhard, 2005; Titov et al., 2005), the Japanese Urgent Earthquake Detection and Alarm System (UrEDAS) in the western Pacific (Saita and Nakamura, 2003) or the German

Published by Copernicus Publications on behalf of the European Geosciences Union. 
Indonesian Early Warning System (GITEWS) in the Indian Ocean (Lauterjung, 2005). The manifold aspects for end-toend tsunami early warning systems include tsunami hazard and vulnerability assessment, perception studies, evacuation modeling, eventually leading to technical requirements for monitoring stations and recommendations for adaptation and mitigation strategies. In large part, scientific studies to date give insight into a single specific part of the early warning process.

Assessing historic or potential future tsunami impacts to coastal communities is presented in the literature over the last few decades. A broad overview of the achievements in tsunami science is given in Synolakis and Bernhard (2006). A variety of numerical tools were developed that are capable of simulating the entire process of tsunami generation, propagation and run-up or parts of this process on either rectangular grids (e.g. MOST in Titov and Synolakis (1998), TUNAMI-N2 in Goto et al. (1997) or unstructured grids (e.g. ANUGA in Nielsen et al., 2005) solving the Nonlinear shallow water wave equations. Higher accuracy was gained when numerical models were developed solving Boussinesqtype equations but with much greater computational cost (e.g. Lynett et al., 2002). A tsunami inundation study dealing with western Sumatra and our focus area presents inundation maps based on historic events and plausible future scenarios deduced from GPS measurements (Borrero et al., 2006) but only on coarse available geometry. Burbridge et al. (2008) present a probabilistic tsunami hazard assessment for scenarios in the Indian Ocean. Regarding the devastating impact of actual tsunamis Reese et al. (2007) analyzed post-tsunami impact by field surveys with the intention to calibrate future models for inundation depth assessment as well as for stability assessment of buildings. Tinti et al. (2005) present an analysis based on eye-witnessed tsunami reports to give insight into the hazard process and impact.

In the field of tsunami vulnerability assessment studies target different aspects of vulnerability. Leone et al. (2007) focus on physical vulnerability correlating physical parameters of buildings visible from space with damage grades surveyed after the 2004 tsunami in Banda Aceh, Indonesia. Papathoma et al. (2003) and Taubenböck et al. (2008a) incorporate multiple vulnerability indicators from the natural and built environment to socio-demographics. With the focus on vulnerable conditions of people a global survey of capacities and gaps for early warning systems, identified warning dissemination and preparedness to act (response capability) as the weakest elements (ISDR Newsletter, 2006). Schneiderbauer and Ehrlich (2006) discriminate "social levels" of vulnerability at sub-national scale. Measuring socio-economic vulnerability to tsunami in the context of early warning means identifying relative differences of spatial and social patterns with regard to access to warning information and compliance of tsunami exposed social groups (Birkmann, 2006). In an actual tsunami warning authorities face various uncertainties of the success of an issued warning: How many people will respond, how fast will they act, what will they do and where will they go (Sorensen, 2000)? The development of evacuation simulations relies strongly on results obtained in the field of transportation modeling. Like in transportation, one can distinguish static approaches, e.g., Sheffi (1985), and dynamic approaches, e.g., Peeta and Ziliaskopoulos (2001). A typical static evacuation simulation is MASSVAC (Hobeika and Kim, 1998). The obvious shortcoming of static models is that they do not capture dynamic effects, which are highly relevant in evacuation situations. Consequently, many dynamic traffic assignment (DTA) models have been applied for evacuation simulations, e.g., MITSIM (Jha, Moore and Pashaie, 2004), DYNASMART (Kwon and Pitt, 2005), and PARAMICS (Chen and Zhan, 2004). Another aspect according to which transportation models may be classified is their granularity: Microscopic models represent every trip-maker individually, whereas macroscopic models aggregate traffic into continuous streams. All of the above DTA packages rely on microscopic traffic models. Further microscopic approaches that have been applied to the simulation of evacuation dynamics are cellular automata (Klüpfel et al., 2003) and the social force model (Helbing et al., 2002). Random utility models are also applicable to the microscopic modeling of pedestrian dynamics (Bierlaire et al., 2003); however, they are yet to be applied in evacuation scenarios.

In comparison to most studies our work focuses on the development of a tsunami early warning information system at high-end geometric and thematic detail. We aim to analyze and identify risk based on the development of hazard scenarios and the assessment of vulnerability of the current system on individual building level. Furthermore, our study tries to incorporate various scientific research fields - engineering, remote sensing and social sciences - to cover manifold perspectives for tsunami early warning. We combine data, methods and results from inundation modeling, urban morphology analysis, population assessment, socio-economic analysis of the population and evacuation modeling. We take the inundation dynamics into account by simulating various hazard scenarios; we measure and quantify the level of exposure; we assess the physical-technical susceptibility and the socio-economic vulnerability of the population; we analyze emerging interactions between the hazard, the vulnerable elements (people, critical infrastructure, etc.) and model dynamic evacuation scenarios with the objective to identify bottlenecks of the situation. The results of this interdisciplinary research serve as a basis for recommendations and identification of related spatial planning efforts to reduce the risk of human and material losses in case of a potential tsunami impact.

The work presented here is embedded in the Numerical Last Mile Tsunami Early Warning and Evacuation Information System (Last-Mile) project (Birkmann et al., 2008a; www.last-mile-evacuation.de). The term "Last-Mile" is understood as synonym for the immediate coastal area, where a potential tsunami wave piles up and eventually hits the 
vulnerable system on land. The project focuses on the urban coastal hinterland of the city of Padang, West Sumatra, Indonesia, which has been indicated as one of the most plausible localities for a tsunami of disastrous proportions in the near future (Borrero et al., 2006).

Padang is the capital city of the Sumatera Barat province in West Sumatra, and with almost one million inhabitants the third largest city on the island of Sumatra, Indonesia (Fig. 2a). The complex and dynamic urban system of Padang features a high concentration of population, infrastructure and economic values. Padang features supra-regional relevance with an international airport, a port as well as binding to the rail network. Thus, the city possesses a central economical role for the coastal region and the mountainous back-country. It is located directly on the coast and partially sited beneath the mean sea level. Off the coast of Padang, the Sunda Arc marks an active convergent plate boundary. Thus, the city is located in a zone of extreme high probability to severe earthquakes and potential triggered tsunamis. According to the tsunami catalogue of the Indian Ocean, which includes about ninety tsunamis, $80 \%$ of the tsunamis originate in the Sunda arc region, where on average tsunamis are generated once in three years (Rastogi and Jaiswal, 2006).

A conceptual overview on risk and vulnerability serves as the outline of this study (Sect. 2). After the introduction of the various data sets used (Sect. 3), the further organization of the chapters is based on the conceptual overview: A hazard and a vulnerability part (Sect. 4). The results from the various scientific disciplines open up into main findings and recommendations (Sect. 5), before we summarize our work and give an outlook on intended progress within the scope of our study (Sect. 6).

\section{Conceptual overview}

Risk specifies something prospective and imaginary, and thus implies uncertainty. In context of disaster risk, the concept of vulnerability has evolved out of the social sciences and was introduced as a response to the purely hazard-oriented perception (Schneiderbauer and Ehrlich, 2004) in the 1970s. There are various definitions and concepts on risk and vulnerability from different schools and disciplines (Birkmann, 2006; Cannon et al., 2003; Correll et al., 2001; Davidson, 1997; IPCC, 2001; Blaikie et al., 1994; Turner et al., 2003; UN/ISDR, 2004); the BBC Framework (Birkmann, 2006) bases on these studies and is used to structure and conceptualize risk and vulnerability assessment within our approach (Fig. 1).

According to the BBC framework, risk is understood as the interaction of the hazard and the vulnerability of a system exposed. Vulnerability itself is considered as a configuration and interaction of physical, demographic, social, economic, environmental and political exposed and susceptible elements as well as coping capacities of these elements

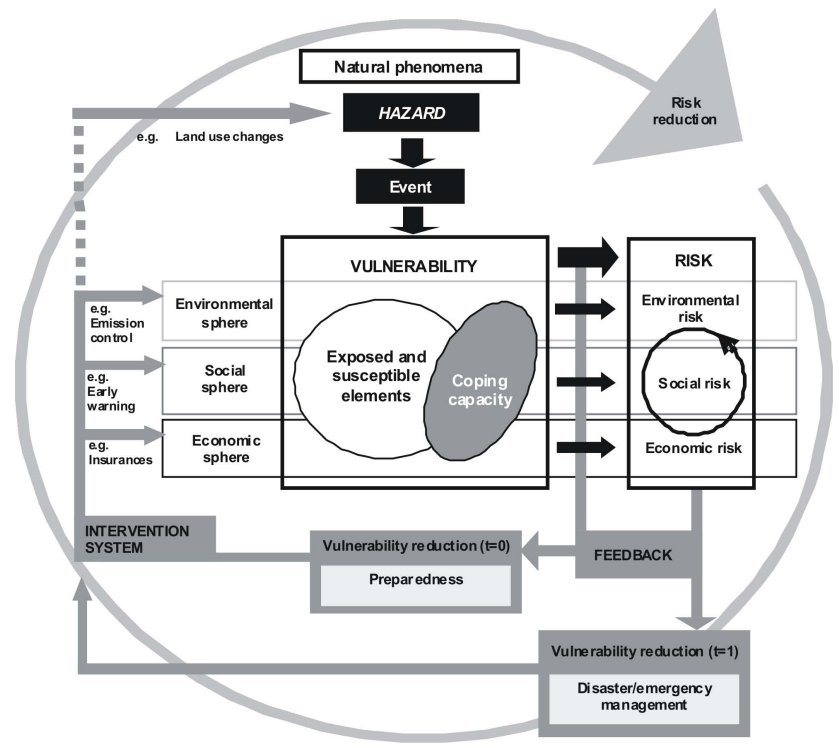

Fig. 1. BBC Framework (Source: Birkmann, 2006, based on Bogardi and Birkmann, 2004 and Cardona, 1999, 2001).

(e.g. social groups, infrastructures, economic sectors) (Eqs. 1 and 2).

Risk $=f($ Hazard, Vulnerability $)$

Vulnerability $=f($ Exposed Elements,

$$
\text { Susceptibility, Coping Capacity) }
$$

The effect of a natural hazard on the objects or people of a particular area/system exemplify the complex interrelationships and emerging domino effects (Taubenböck et al., 2008a). The BBC-framework outlines two potential paths for reducing disaster risk and vulnerability: 1) preventive measures such as spatial planning and awareness raising before a disaster manifests (t: 0$)$; 2) disaster management such as evacuation and emergency response during a disaster (t: 1) (Birkmann, 2006). The intervention system - e.g. existing emergency management plans - has direct effects on the configuration of the overall vulnerability and determines the level of risk. One main advantage of this framework is the clearly indicated feedback loop system of the measures (intervention system) in reducing the risk. This implies that the entire risk and vulnerability assessment should take into consideration the existing or planned measures and that, at the same time, the existing and planned measures should ensure vulnerability reduction.

The BBC conceptual framework stresses the fact that vulnerability assessment should take into account exposed, susceptible elements and coping capacities (we follow this structure in Sect. 4). They determine the likelihood to suffer harm due to potential tsunamis. The vulnerability assessment in tsunami early warning context refers to identify the causality 
of ineffective responses to early warning generating loss of lives (and livelihoods) during an emergency situation. According to UN/ISDR (2006) this conforms to the weakest elements of early warning systems "warning dissemination and preparedness to act".

Based on this conceptual framework we address in our study the following specific questions about tsunami risk components to cover required information for appropriate recommendations and decision-making at the "last-mile":

- What kind of inundation dynamics and what time frames are expected?

- How many structures and people and which groups of people are exposed for particular hazard scenarios?

- What factors influence different responses/behaviour to the tsunami early warning and coping capacity of various social groups in emergency situation?

- Which bottlenecks arise during the process of evacuation?

- Which scenario-specific decisions and recommendations have to be met to minimize disaster risk?

\section{Multidisciplinary requirements for data sets}

Problems associated with hazard analysis, risk and vulnerability assessment, and developing risk reduction measures are inherently spatial in nature. High resolution and updated data on topography, bathymetry or thematic maps of the city of Padang were not available or existing. Therefore, various remotely sensed and hydrographical data sets were acquired as well as field surveys containing household questionnaires were conducted to remedy the gap.

\subsection{Remotely sensed data}

We use high resolution satellite imagery from the Ikonos sensor with geometric capabilities of $1 \mathrm{~m}$ in panchromatic and $4 \mathrm{~m}$ in multispectral (blue, green, red and nir) bands to extract highly detailed information on the individual physical objects of complex urban areas - buildings, streets and open spaces. In addition an aerial survey was conducted in Padang gathering appropriate data with even a higher resolution using the Multi Functional Camera (MFC). The unique MFC system is one of the most advanced digital aerial line scanner systems worldwide. Characteristics of the camera include synchronous image data acquisition, with up to $16 \mathrm{~cm}$ spatial resolution, and detailed and highly automated processing of Digital Surface Models (DSM). The MFC system is one of few systems available today that is capable of producing image and elevation data with the appropriate radiometric and geometric quality for this kind of project.
Generation of a homogeneous map requires postprocessing of all image data. The Ikonos data were pansharpened and were subject to atmospheric corrections utilizing the ATCOR (Atmospheric and Topographic Correction) Software (Richter, 1996). The airborne data were processed using internal software, developed by the DLR to add navigability, as recorded by GPS and the Inertial Measurement Unit (Börner et al., 2008). The resulting data were true orthophotos with a resolution of $25 \mathrm{~cm}$. The data were mapped and delivered in units of UTM/WGS 84. The aerial survey was accompanied by a building facade survey. Facades of sample sections of the town were photographed and their positions measured by GPS. A database of buildings was permits identification and visualization of evacuation and infrastructure relevant buildings in the 3-D city model.

After the successful aerial survey mission, the raw data had to be further processed, including the radiometric enhancement and mosaicking of all aerial transects. The derived surface model with a horizontal as well as vertical resolution of $25 \mathrm{~cm}$ required some manual topographic corrections such as break lines along rivers and coastal areas, which are necessary to ensure the topological correctness of the derived Digital Elevation Model (DEM) that forms the basis for the hydrodynamic calculations under consideration (Moder et al., 2008). Finally, a cross-check was conducted to ensure quality of the topographic datasets by means of fast-static GPS measurements at twelve randomly chosen coordinates in Padang. The accuracy resulting from this procedure is in the range of $10 \mathrm{~cm}$ for the horizontal and $20 \mathrm{~cm}$ for the vertical dimension. In addition, an interferometric digital elevation model (DEM) based on X- and C-band data from the Shuttle Radar Topography Mission (SRTM) acquired in February 2000 was available to analyze the terrain situation. It is a surface model with a pixel-spacing of $25 \mathrm{~m}$ and a vertical accuracy of 4-6 m (Marschalk et al., 2004).

\subsection{Hydrographical survey data}

The main objective of the conducted hydrographical multibeam survey off the coast of Padang was to geometrically enhance the existing set of bathymetrical data originating from former singlebeam surveys and nautical charts. Therefore we equipped a local fishing boat with a SeaBeam 1185 echo sounder (L3 Communications Elac Nautik GmbH) to a customized bracket at the hull. An inertial measurement unit (F180, CodaOctopus) and a global positioning system (Trimble 5700 receiver) were mounted additionally. Throughout the ship cruise profiles of conductivity, temperature and depth were taken by a CTD probe along the vertical to adjust the sound velocity for the sonar system.

The horizontal positioning was optimized in postprocessing by means of differential GPS using correction data from the PSKI base station on Sikuai island. Correction for tidal influences was accomplished by application of time series derived from tide station at Teluk Bayur harbour. The 

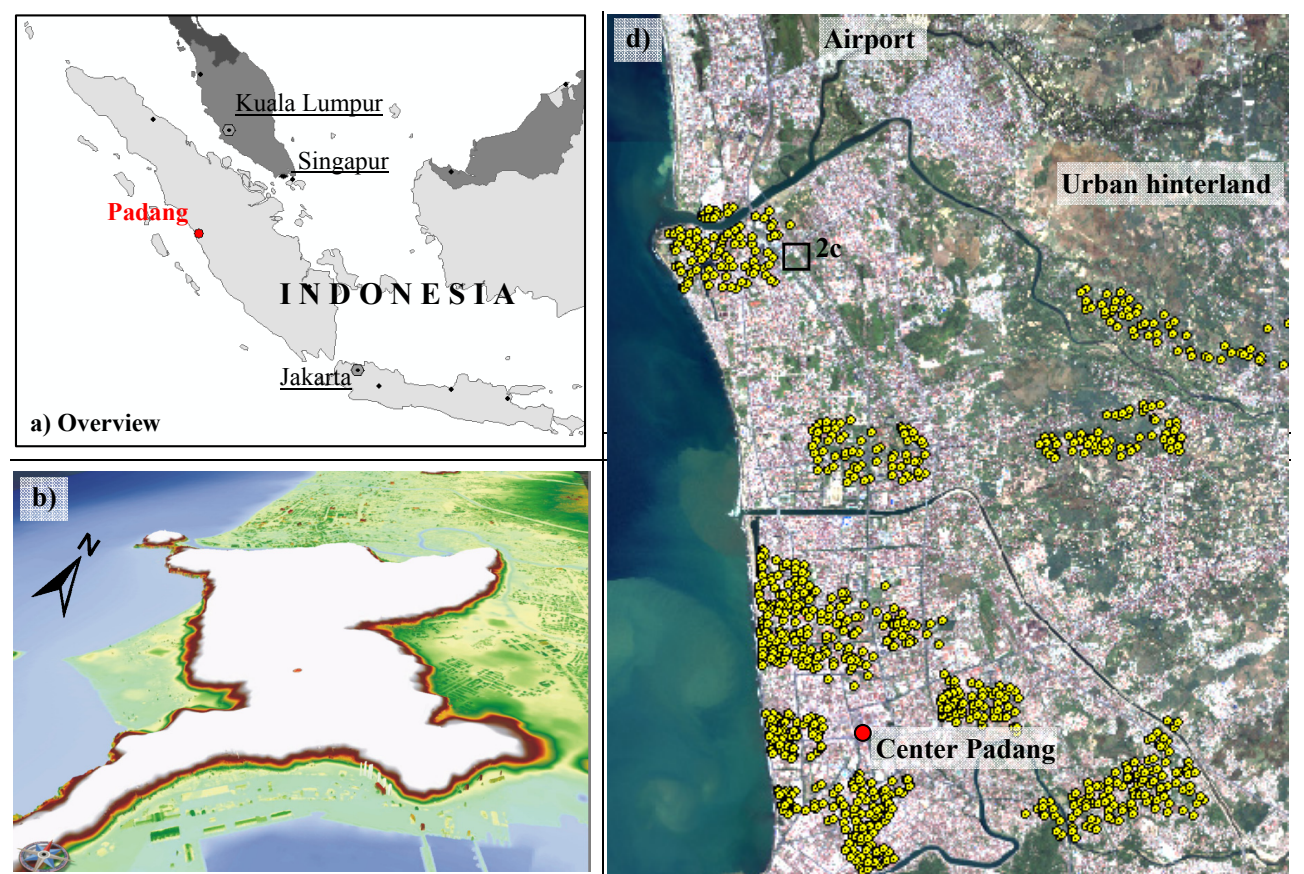

(1)

3-dimensional view showing bathymetry and topography from $-50 \mathrm{~m}$ (blue) to $0 \mathrm{~m}$ (green) to $10 \mathrm{~m}$ (brown) and higher (white)

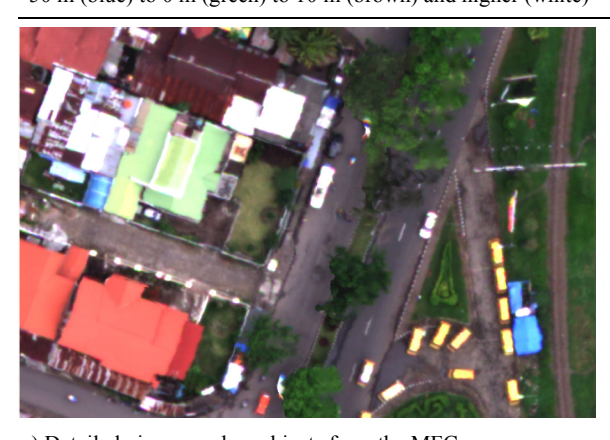

c) Detailed view on urban objects from the MFC

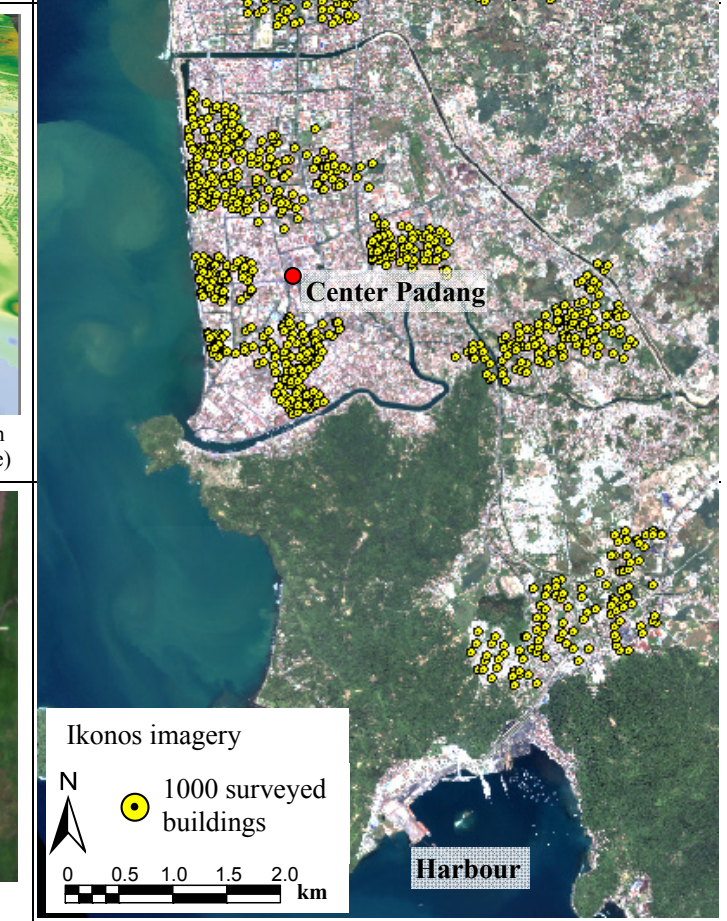

Fig. 2. Overview on the location of the study area Padang, Indonesia and presentation of the acquired data sets.

area covered by the conducted multibeam survey comprises approximately $42 \mathrm{~km}^{2}$. Water depth varies from $-3.14 \mathrm{~m}$ to $-50.65 \mathrm{~m}$ in the area of interest. The post-processing of the surveyed bathymetry was done with the software "Caris Hips \& Sips". As a result a surface model of the surveyed area with a pixel-spacing of $3 \mathrm{~m}$ was produced. All water depths are referred to mean sea level.

Even if an overall quality and error estimation for the integrated measurement system is difficult, the accuracy of single components could be specified instead. The inertial measurement unit has an attitude accuracy of $0.061^{\circ}$ and a heading accuracy of $0.175^{\circ}$. The accuracy of the post-processed GPS data is in the range of $5.0-7.0 \mathrm{~cm}$ whereas the sound velocity calculation by the CTD probe is accurate to $0.2 \mathrm{~m} / \mathrm{s}$. The accuracy of the echo sounder device is specified as $>0.2 \%$ of the sounding depth.

\subsection{Socio-economic data}

Existing statistical data only provide limited information on socioeconomic parameters of the population. From the census in 2000 no specific information on early warning and disaster preparedness at the local level/sub-district level are available. For up-to-date knowledge on socio-economic parameters a survey was conducted. The needed information was primarily collected by means of geocoded household questionnaires with a sample size of 1000 households in Padang (Setiadi, 2008; Birkmann et al., 2008b). The distribution of the questionnaire samples is selected based on the physical analysis of the urban morphology (Sect. 4.2.1), function of the building, the geographic location and external socio-economic information on district level to cover the entire spatial and thematic spectrum of the urban landscape (Fig. 2d). The questionnaires encompass questions on the general socio-demographic and socio-economic 
characteristics of the households such as age, main and daily activities, income, education, and on specific themes related to knowledge and experience on tsunami warning and evacuation, access to warning media, up to risk perception and intended behaviour. Relationships between parameters under respective themes are analyzed using both descriptive statistics and multivariate analysis methods. This analysis takes into account the spatial parameters that contribute to the people's perception and capability to conduct evacuation, e.g. distance of the household to the coast and accessibility of safe places. In order to validate the analysis results, qualitative on field data collection at the later phase of the study is planned.

Figure 2 displays a multi-scale overview for the study area Padang and acquired data sets. It shows the location of Padang in Southeast Asia (Fig. 2a). It also shows the highly detailed bathymetry and the digital elevation model (Fig. 2b). The detailed view of the MFC data displays the highly detailed geometric capabilities of the sensor (Fig. 2c). The Ikonos data provide an overview on the heterogeneous, small-scale and irregular urban pattern characterized by the fundamental physical elements of buildings, streets and open spaces in the entire urban area of Padang and indicates locations of the center or transportation hot spots. It also displays the spatial distribution of the sampling households, which was intended to cover the complete spectrum of the urban system - from buildings in the urban centre to the suburbs, from the coast to the urban hinterland and from small and low structures to large and high-rise buildings (Fig. 2d).

\section{Interdisciplinary information system}

This chapter specifies methods and results from the various scientific fields - inundation modeling, urban morphology analysis, population assessment, socio-economic analysis of the population and evacuation modeling - and their interlinkage. The aim is to highlight different components of the conceptual framework (Fig. 1) to substantially contribute to tsunami early warning and an evacuation information system. Knowledge on the probability, severity and the spatial impact of the hazard - in our case a tsunami - is the first element for an intermeshing information system. The second element is the vulnerability of a system, in our case the coastal urban area of Padang, with its exposed elements like structures, population or economy, with its susceptibility and with its coping capacity. Interdisciplinary collaboration aims to highlight and analyze dependencies within the process chain to link the various different scientific perspectives for a more holistic understanding of disaster risk and its management.

\subsection{Hazard}

A tsunami is a set of ocean waves caused by any large, abrupt disturbance of the sea surface (Bernhard et al., 2006). These

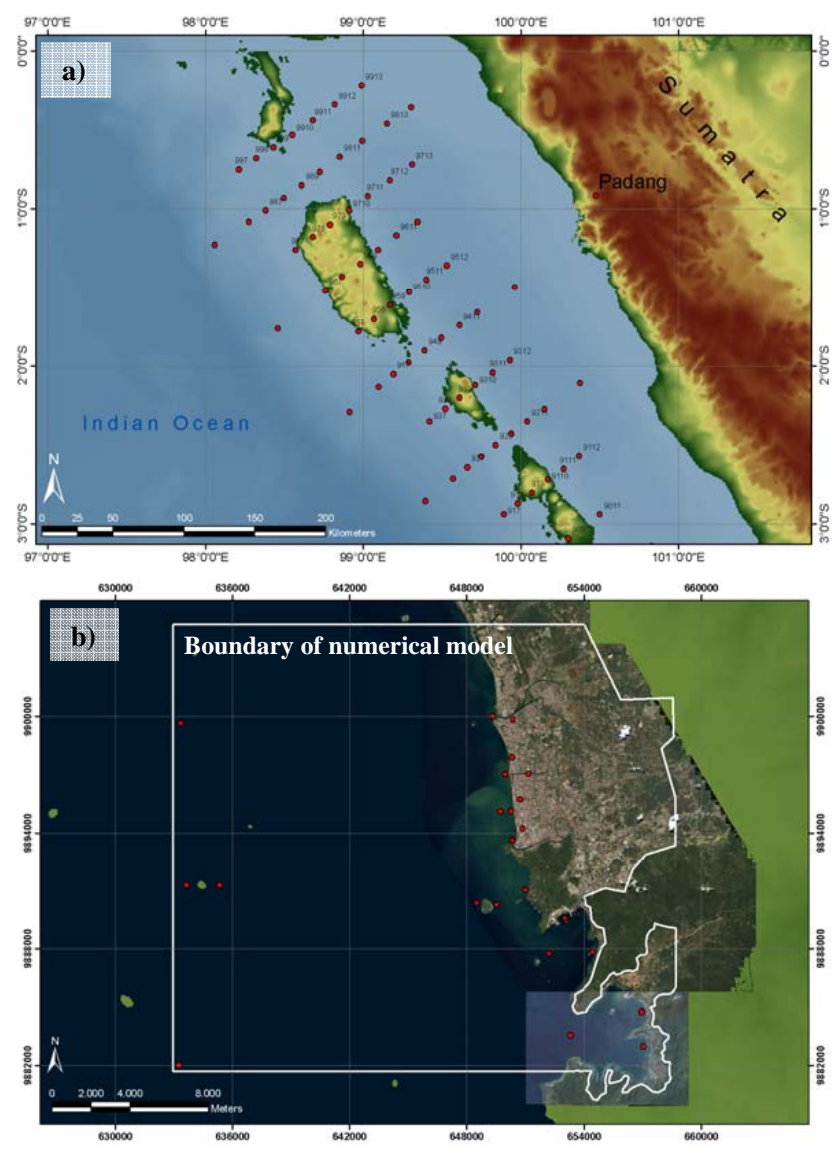

Fig. 3. (a) Locations of epicentres for the pre-calculated scenarios by AWI available with $\mathrm{M}_{w}=8.5$ and $\mathrm{M}_{w}=9.0$; (b) Overview of the modelled area, Padang city, Teluk bayur and the oil harbour, the wave is introduced into the model at the western boundary.

disastrous waves could possibly be triggered by undersea earthquakes, land slides or volcano ruptures. To assess the impact of tsunamis, in-depth studies of inundation dynamics extracted from hydrodynamic simulations could contribute widely, where detailed information about velocity fields and flow depth is needed for evacuation simulation in coastal urban areas. From the field of coastal engineering these parameters could be obtained by solving the appropriate equations describing the predominant character of the flow field. Tsunamis are referred to as surface gravity waves with a typical wave length that is several times the water depth. This wave phenomenon is often represented mathematically by the nonlinear shallow water (NLSW) equation or Boussinesq type equations (Pedersen et al., 2008). We have chosen NSLW for the hydrodynamic study of our project area due to computational costs and since dispersive effects in the near shore zone are less dominant.

The computational domain comprises an area of about $580 \mathrm{~km}^{2}$ that is bordered on the southern, western and northern part by the Indian Ocean. In the east of the domain the 


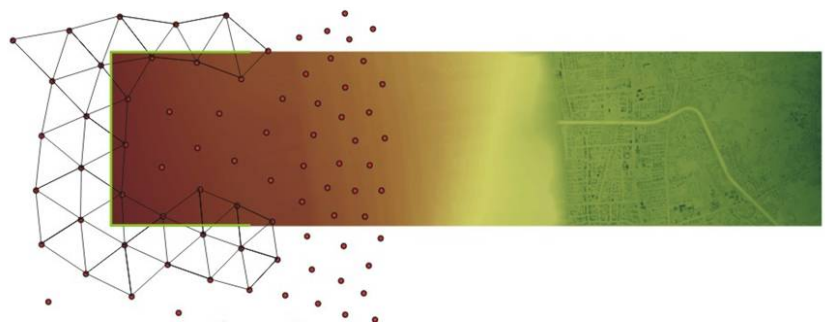

Fig. 4. General idea behind coupling the two different numerical models, light green line indicates the interface between AWI and ANUGA model, red dots represent AWI mesh nodes, conserved quantities are linearly interpolated to the ANUGA boundary, and rectangular box represents parts of the ANUGA domain.

city of Padang is introduced taking into account the highlyresolved digital elevation and surface models surveyed by an airborne remote sensing campaign (cp. Sect. 3.1). Besides the main part of Padang we include the economically fundamental harbour regions Teluk Bayur and the oil harbour in the south of Bungus Bay. In addition we add a strip of $3 \mathrm{~km}$ width in the north made up of less accurate elevation data available from the Intermap campaign (Intermap, 2007). The landward boundary is confined by the $80 \mathrm{~m}$ contour line. A great demand for highly-resolved bathymetry in the nearshore zone and topography for adequately modeling overland flow was stated e.g. by McCloskey et al. (2008). Smallscale bathymetry variations affect modeling results to a major order (Borrero et al., 1997) and possible time-dependent changes in coastal topography need to be considered when numerical models are validated (Borrero et al., 2006). Coping with these constraints we conducted a hydrographical survey off the coast of Padang in 2007. This $3 \times 3 \mathrm{~m}$ grid obtained from that campaign is merged into a final digital elevation model together with the newly surveyed topography (cp. Sect. 3.1). Amongst these highly-resolved data sets we use SRTM data, GPS measurement, digitised nautical charts, General Bathymetric Chart of the Oceans (GEBCO) and C-Map bathymetry (Jeppessen Marine) products in order to finalize the geometrical basis for the numerical modeling. Given the fact that we used the most accurate, highly resolved and contemporary datasets for bathymetry and topography, time-dependent changes have been considered in the geometry model sufficiently. Other time-dependent effects due to sediment transport or debris flow are beyond the scope of this study.

For the tsunami inundation modeling a hybrid approach was chosen to study wave propagation from the source onto dry land. In a basic step the source modeling and the deep-water propagation was carried out by Alfred-WegenerInstitute (AWI) based on the model TsunAWI (Harig et al., 2007). The NLSW equations are employed as a basic set of equations that are solved on an unstructured finite-elements mesh (Behrens, 2008). Subsequently a hydrodynamic inun- dation modeling tool called ANUGA (Australian National University and Geoscience Australia, Nielsen et al., 2005) is employed for the computations of run-up and on-land flow for the project area due to effective shock capturing methods and domain decomposition strategies. The interface between both numerical models is designed to linearly interpolate model outputs from TsunAWI onto the mesh nodes at the ocean boundary of the ANUGA domain (Fig. 3a). We have chosen to simulate the inundation of the city of Padang in a hybrid model mainly due to computational cost and modeling time considerations. Additionally ANUGA assumes that all spatial coordinates are within one UTM zone. Modeling the end-to-end process of generation and propagation of tsunami as well as inundation in a single model is therefore currently inapplicable for the Padang area by ANUGA software since the earthquake source and the area of interest are not always in the same UTM zone.

ANUGA uses a finite-volume approach to solve the nonlinear shallow water wave equations in conservative form. A spatially varying triangular mesh is used to discretize the considered area of interest. The conserved quantities are water depth and horizontal momentum in $\mathrm{x}$ - and $\mathrm{y}$-direction (Nielsen et al., 2005). A detailed description of the applied numerical scheme can be found in the work of Zoppou and Roberts (1999). The chosen coupling strategy only allows for unidirectional propagation of the incident wave into the ANUGA domain. Care must therefore be taken when the domain is established since both models run independently from each other and don't interact or exchange results while simulations are being executed.

A twofold strategy is adopted throughout our modeling for the city of Padang in order to satisfy the fact that the urban topology of our focus area is densely built-up. On the one hand we employ two different house masks derived from the remotely sensed imagery. The finest house mask bases on the real building situation in the city including size, form and height of every individual house (Sect. 4.2.1). In addition, we use a coarse house mask combining the individual buildings per unit (blocks which are defined by the street network) to one quadrangle with a size corresponding to the real size of all individual buildings summed up. A major reason for running models with both DSM and DEM plus house masks is that it presently is not fully understood how macro-roughness elements could be taken into account in these kinds of hydrodynamic studies. The coarse house mask reduces the processing time significantly. On the other hand we employ the highly-resolved digital surface model that is sufficiently represented by a maximal triangle area of about $20 \mathrm{~m}^{2}$. The maximal triangle area in the triangular mesh used is a measure for the quality of the hydrodynamic study. The values chosen are optimized on the one hand to capture all relevant topographic features and on the other hand to reduce needless computation time. As evacuation routes and upgrading recommendations are a focal point in our interdisciplinary study, the resulting flow fields need to represent at least major roads, 


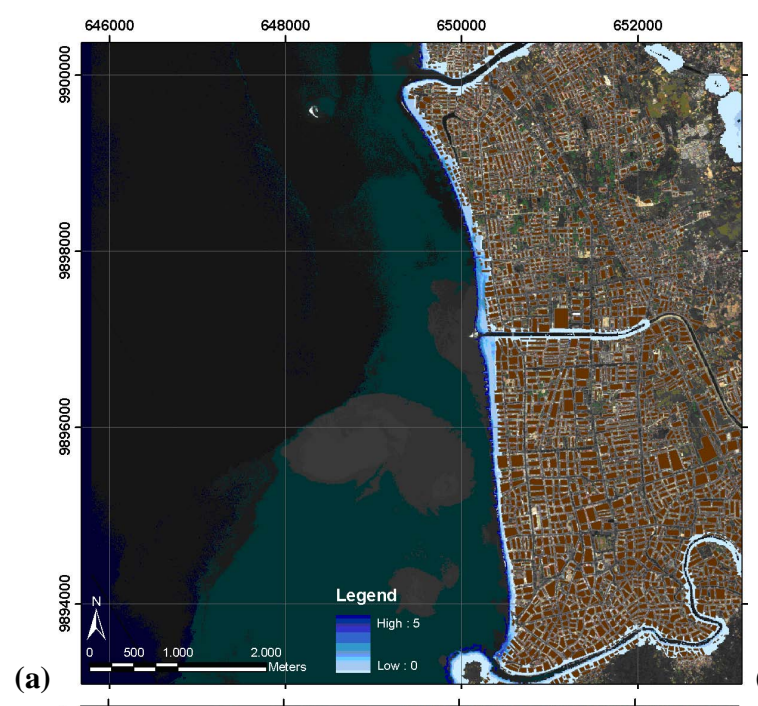

(a)

(c)

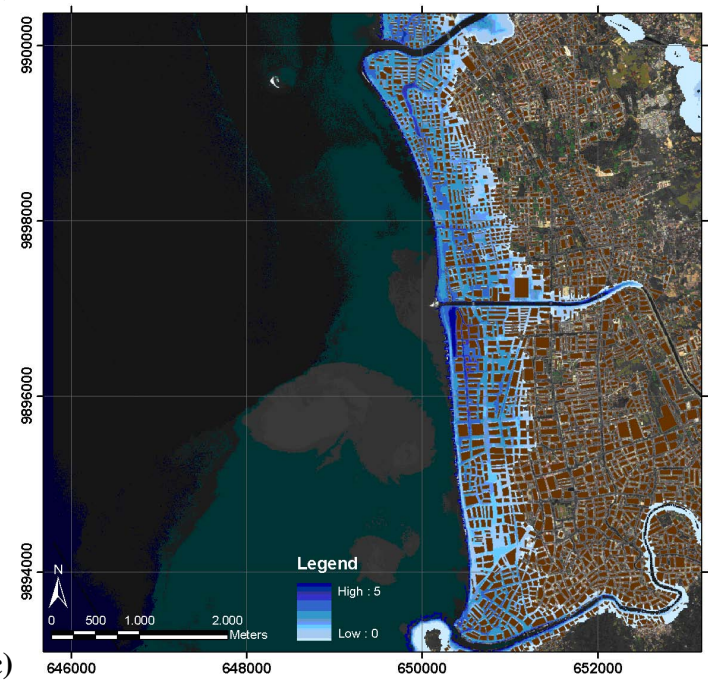

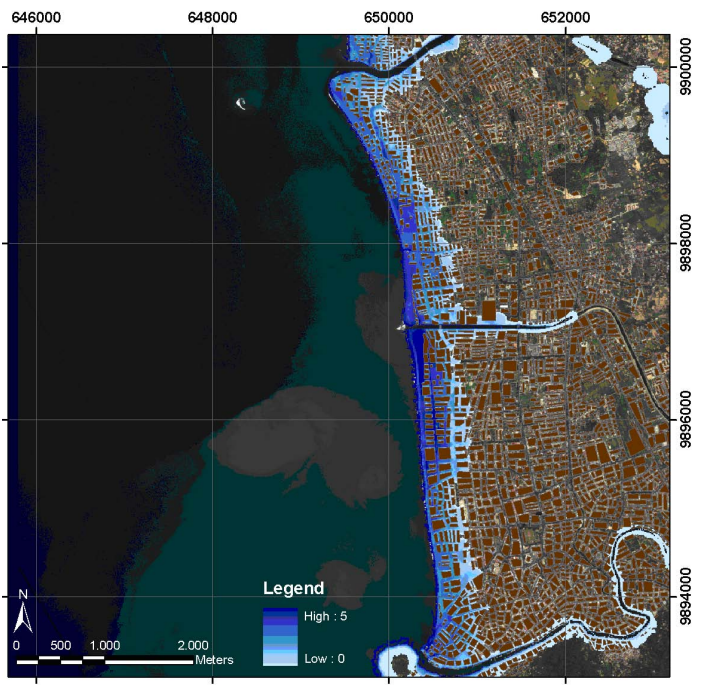

(b)

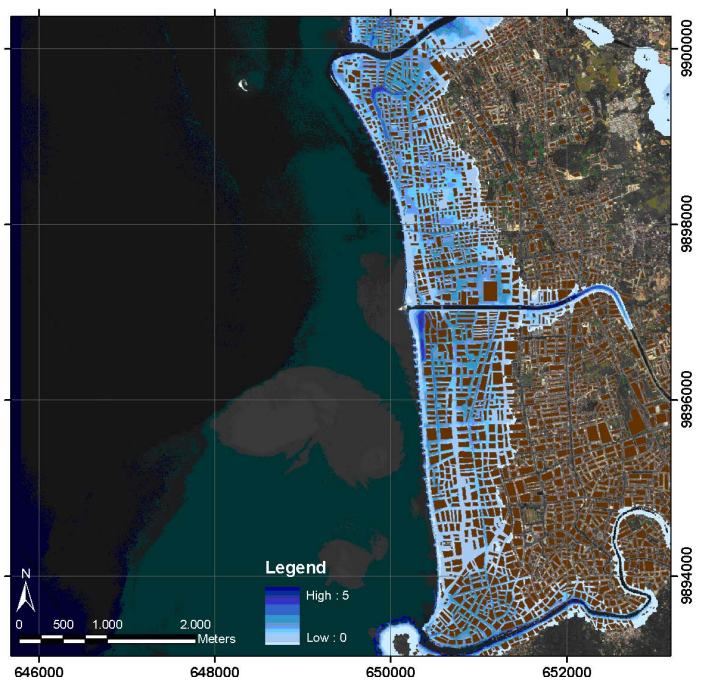

Fig. 5. Sequential snapshots of combined inundation extend map and inundation depth map for Padang City, times are measured with respect to the arrival of the leading wave at the shoreline at zero seconds. Upper left: Sequence at 60 s, upper right: Sequence at $240 \mathrm{~s}$, lower left: Sequence at $420 \mathrm{~s}$ and lower right: Sequence at $600 \mathrm{~s}$.

streets and waterways in the city to compare with evacuation simulation adequately (cp. Sect. 4.2). This requirement is addressed by using meshes that are in the range of $10-20 \mathrm{~m}^{2}$ for the city of Padang.

A common approach to calibrate and validate numerical studies is to compare them with historic tsunami inundation patterns, but for the city of Padang, the availability of validation events for our numerical studies is very poor (Borrero et al., 2006). Therefore we decided to rely on a large set of pre-calculated scenarios with spatially distributed epicentres (Fig. 3a). From the considered scenarios the medium warning time measured from the earthquake event until the arrival of the leading wave front is approximately $40 \mathrm{~min}$, minimum 23 min and maximum 65 min (oral communication with AWI). Based on these scenarios hazard zones are iden- tified and communicated to conduct adjacent hazard and risk assessment studies (cp. Sect. 4.2). The pre-calculated scenarios were taken as boundary conditions for both a preliminary study as well as for the full model domain. The result from the preliminary study revealed some important hints on the further modeling published in Goseberg et al. (2009) and Goseberg and Schlurmann (2008). The most striking fact is that the employments of highly-resolved data sets in contrast to commonly available data lead to channelized flow in major streets together with much higher currents. When a more sophisticated DEM is used not only flow velocities are amplified, but also flow depths and water levels directly at the shoreline are increased.

Finally these conclusions from the preliminary study could be confirmed and deepened as we analyzed first results from 

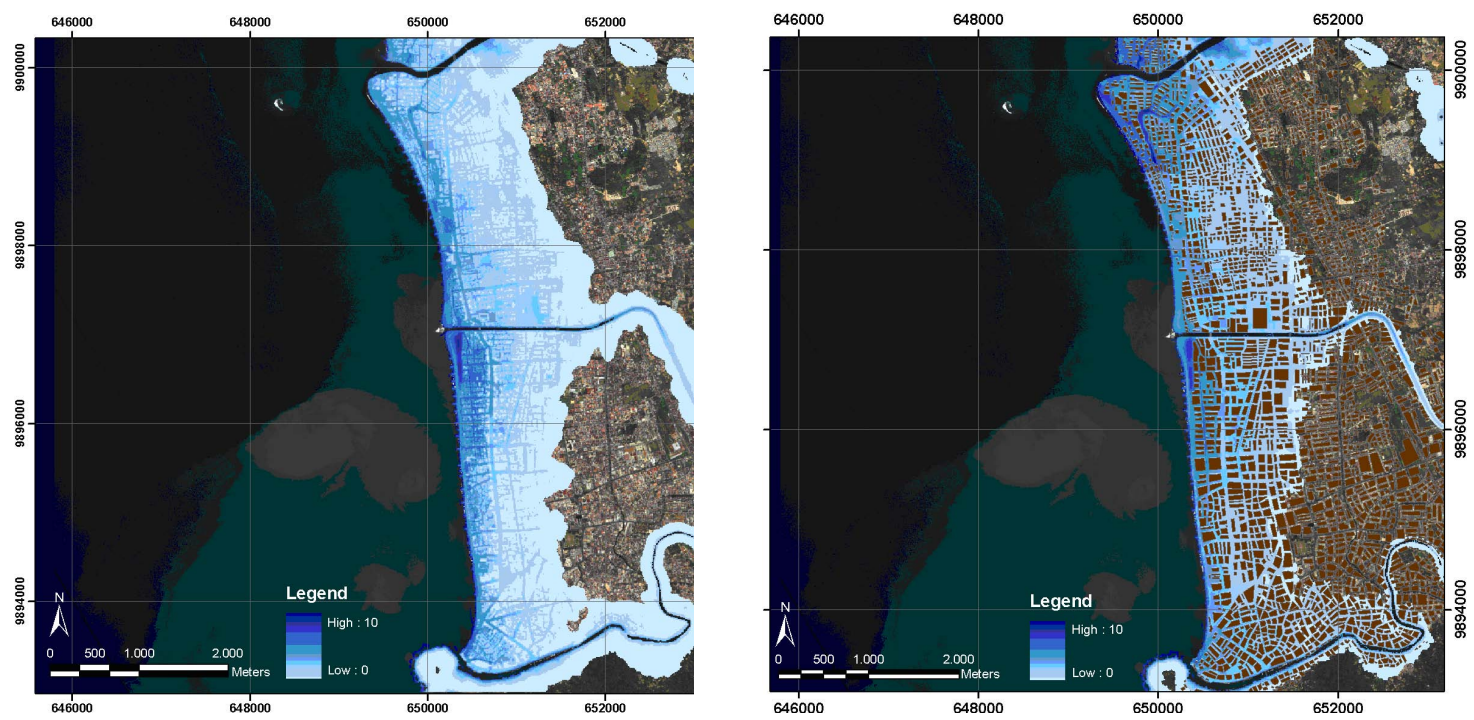

Fig. 6. Exemplary flood extent maps for the different modeling strategies applied. Left: Maximum inundation depth [m] for a model with digital surface model; Right: Maximum inundation depth [m] for a model using a medium resolution house mask derived from remotely sensed data.
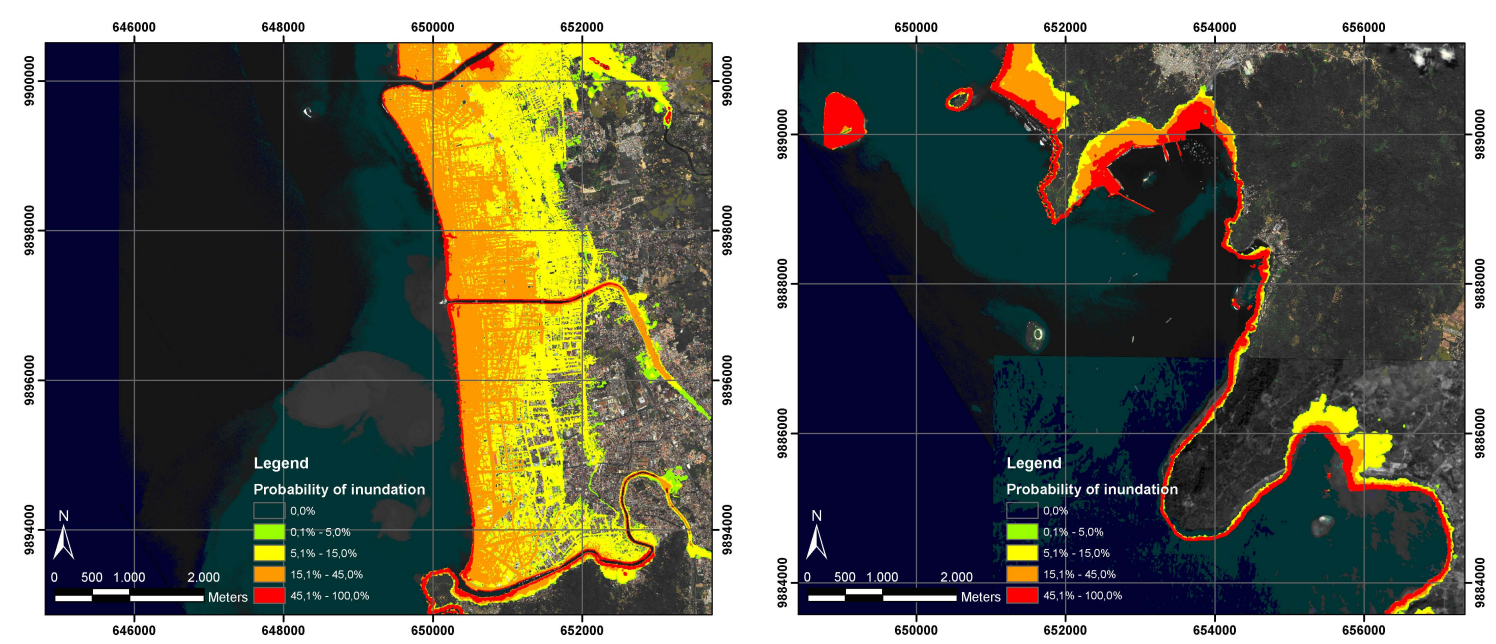

Fig. 7. Exemplary hazard maps from preliminary results of our multi-scenario approach compiled from 21 scenarios with underlying DSM model, counts are normalized by the maximal number of scenarios, left: city center of Padang, right: harbour Teluk Bayur south of the city.

the main study of the domain. In this paper we select only two different tsunami sources to show results with respect to the interdisciplinary approach. For details of tsunami sources we refer to Harig et al. (2007). Figure 5 presents sequential snapshots of inundation dynamics for a given $\mathrm{M}_{w}=9.0$ exemplary event south-east of Pulau Siberut for the model runs with the underlying digital elevation model and house masks. These maps combine inundation extent and spatial information about water depth for the given point of times with respect to the arrival of the leading wave at the shoreline at zero seconds. It becomes apparent that areas near major channels and rivers draining the coastal plain are affected earlier than areas more distant to the water bodies. Canalised flow pattern are generally observed when house masks are used instead of digital surface models. As a matter of fact, this flow pattern results in higher water levels near the coast and higher velocities where house polygons are absent in the domain. On the contrary, more distant areas to the shore face significantly lower water levels compared to model runs with DSM.

Figure 6 shows maximum inundation extents for two different model runs for the two modeling strategies discussed above. On the left hand side maximum inundation is plotted using the digital surface model of Padang. Due to the mesh resolution open spaces and built-up areas are not distinguishable from the result, since buildings that are clearly represented in the DSM degenerate under the applied mesh 
interpolation algorithms. Nevertheless, building structures from the DSM affect model results to a significant level compared to plain DEM that are commonly used for such simulations. We found that using DSM data or DEM data together with a house mask for our numerical studies, inundation extent is less compared to simulation runs using only DEM data. That is due to the fact that flow is impeded by the existents house features in the model. The overland flow is reflected or decelerated while interacting with or being reflected at houses. On the other hand maximum inundation plotted for a simulation combined with a medium resolved house mask influences inundation dynamics as well.

Finally we deduced probabilistic hazard maps from the modeling approach discussed above. The hazard maps presented in Fig. 7 are compiled from the scenarios already post processed $\left(\mathrm{M}_{w}=9.0\right)$ by means of counting any inundated raster cell in each scenario. For the probabilistic analyzes inundated raster cells get a value of 1 and dry raster cells a value of 0 . The resulting hazard map is deduced by summing up the available scenarios. Figure 7 shows normalized values with respect to the maximal number of tsunami scenarios in the same moment magnitude classified in 4 hazard zones. The resulting map products are finally being delivered to assess perspectives of vulnerability and to improve evacuation planning.

\subsection{Vulnerability}

With respect to our conceptual guideline - the BBC framework - risk is the interaction of the hazard (cp. Sect. 4.1) and the vulnerability of a system exposed. In the following section we attempt to measure and analyze vulnerability considered as a configuration and the interaction of exposed elements and their susceptibility as well as coping capacities of these elements (e.g. social groups, infrastructures, economic sectors).

\subsubsection{Exposed elements}

Exposure of elements is an inherently spatial problem. Remote sensing is a suitable scientific field to provide areawide, up-to-date and accurate information on the urban land cover and its spatial structural pattern - the exposed elements. Based on the Ikonos imagery (Fig. 2d) we use a combination of an automatic object-oriented, hierarchical classification methodology (Taubenböck and Roth, 2007; Kass et al., 2007) and subsequent manual enhancement to derive a thematic land cover classification. The automatic classification approach resulted in $86.1 \%$ accuracy. Problems are automatic delineation of individual buildings in highly dense built-up areas as well as the automatic differentiation between certain roof types and sealed areas, which made the manual enhancement necessary. The results are eight classes mapping the urban structure - houses, streets, sealed areas, grassland, trees, wetland, bare soil, and water. No ground truth data were at hand for an accuracy assessment. Thus accuracy has been analyzed by a randomization of 500 checkpoints and a subsequent visual verification process between the classification and the Ikonos imagery calculating an error matrix using producer and consumer accuracies. The overall accuracies resulted in $97 \%$ correct classified pixels.

Value-adding from 2-D land-cover information to a 3D city model has been performed. Using the digital surface model in combination with the building mask we assess the height of individual structures. In addition we calculate building sizes, roof types, and built-up density (Taubenböck et al., 2008b). Utilizing the field work experience in combination with the physical parameters of the individual buildings - size, height, location, alignment and roof type - land use is assessed as an additional feature of every building in the entire urban landscape of Padang. This enables to differentiate between residential, mixed, commercial and industrial usage on a basic level. Thus, the city model even enables a basic localization of economic focal areas. A higher thematic specification is integrated using field work information to localize critical infrastructure like hospitals or schools. The orographic condition of the urban region of Padang utilizing the digital elevation model completes the urban environment of the coastal city. Thus, a three-dimensional city model displays the complex, heterogeneous and fine-scale urban morphology and urban land use in a very detailed manner. This product displays essential basic information to know "what" is "where" in the city of Padang. It also provides the spatial basis for interdisciplinary research: The building mask is used as input parameter for inundation modeling of a potential tsunami (Sect. 4.1) and the derived street network is used for evacuation modeling (Sect. 4.2.2). Furthermore the 3-D city model is used to systematically distribute the survey samples (Sect. 4.2.2). Multi-layer analysis allows quantifying and localizing exposed elements of the urban landscape. Figure 8 shows a perspective view from the south on the city model of Padang.

Static urban morphology characterizes an urban agglomeration. But the dynamics of its population also distinguish the urban exposure. We correlate the static element of physical urban structures with the dynamic element of spatial and temporal behaviour of the population by means of the city model and surveyed data on punctual population information. Utilizing the building size and its particular height usable building spaces (living spaces) are calculated. Thus, calculation of average number of inhabitants per square meter is derived based on 500 surveyed geocoded sample buildings distributed around Padang (Taubenböck et al., 2008c). The mathematical concept of bottom-up extrapolation has been presented in detail by Taubenböck et al. (2007). A linear extrapolation algorithm projects the people proportionally to the living spaces of the particular house. Accuracy assessment has been carried out resulting in $86.73 \%$ compliance. In addition the detailed knowledge on the usage 


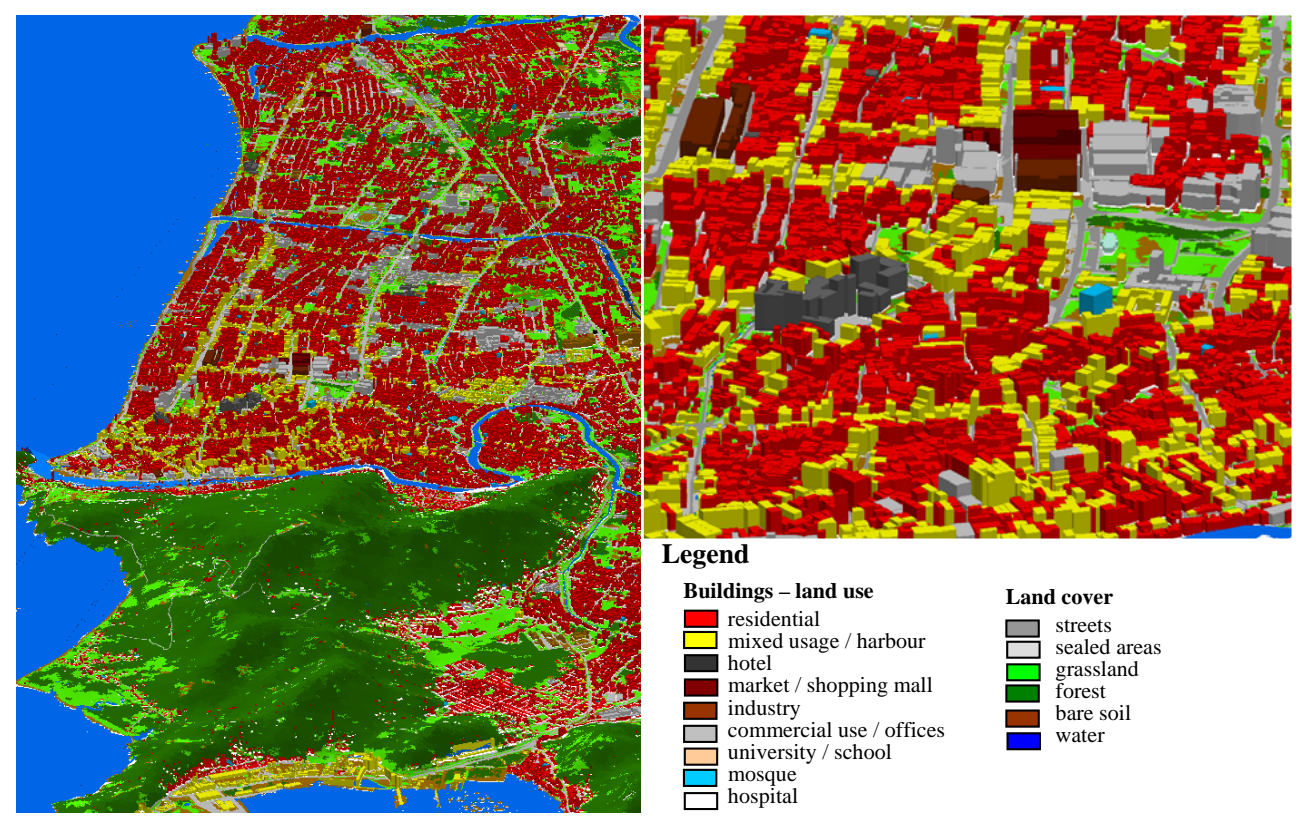

Fig. 8. City model of Padang derived from high resolution satellite data and a digital elevation model (Intermap, 2007).

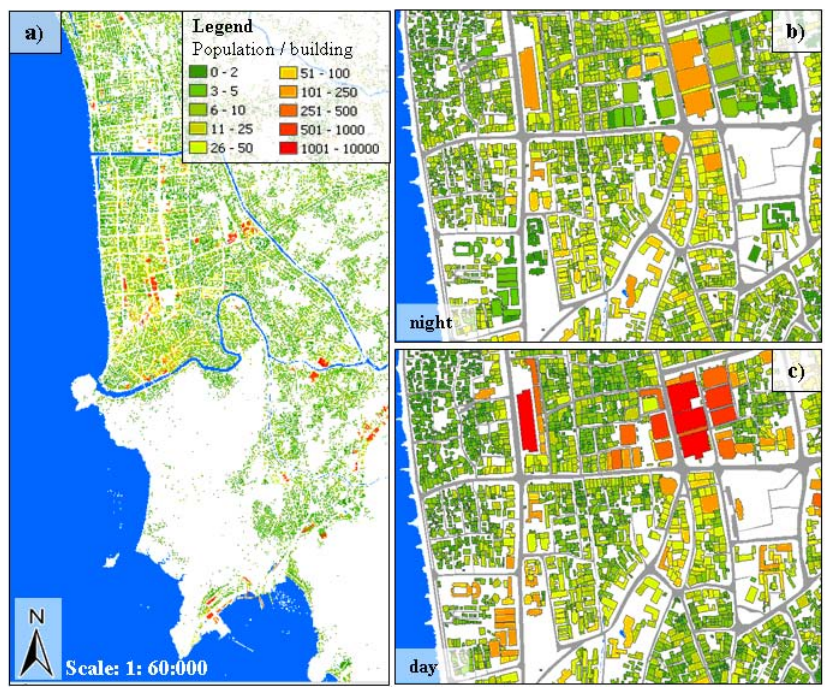

Fig. 9. Population distribution on building level.

of the buildings is at hand. Thus, the bottom-up extrapolation algorithm is calibrated on the different utilization of the buildings - residentially, mixed or commercially used - with respect to the time of day. From the questionnaire, day- and night-time population for the sample buildings are at hand, which is included to assess on average the quantity of people per building with respect to usage. The result is a highly detailed knowledge on the dynamic spatial behaviour and time-dependent whereabouts of people within the complex urban landscape (Fig. 9). Thus, a spatial shift in exposure is mapped that influences location and quantities of potentially affected people in dependency of the time of day.
Table 1. Quantification of affected buildings and time-dependent assessment of affected people with respect to the hazard map (Fig. 7).

\begin{tabular}{lrrrrr}
\hline $\begin{array}{l}\text { Name of } \\
\text { zone }\end{array}$ & Probability & $\begin{array}{r}\text { Buildings } \\
\text { affected }\end{array}$ & $\begin{array}{r}\text { Buildings } \\
\text { affected }\end{array}$ & $\begin{array}{r}\text { People affected } \\
\text { Day-time }\end{array}$ & Night-time \\
\hline No risk & $0.0 \%$ & 50.657 & $57.56 \%$ & 285600 & 281500 \\
Low risk & $0.01-5.0 \%$ & 4.213 & $4.79 \%$ & 36900 & 32400 \\
Medium risk & $5.01-15.0 \%$ & 17.418 & $19.79 \%$ & 98800 & 102100 \\
High risk & $15.01-45.0 \%$ & 14.308 & $16.26 \%$ & 81900 & 75700 \\
Extreme risk & $45.01-100.0 \%$ & 1.408 & $1.60 \%$ & 9500 & 7200 \\
Total & & 88.004 & $100 \%$ & 512700 & 498900 \\
\hline
\end{tabular}

Interdisciplinary combination of the hazard map, the 3D city model as well as the time-dependent population distribution allows now the probabilistic and quantitative assessment of scenario-dependent affected buildings and people. Table 1 shows the results for the 4 risk zones and reveals for the worst case scenario in our test area (Fig. 2d) that overall 37347 buildings would be inundated in different risk zones and 227100 people at daytime and 217400 at nighttime would be at risk.

\subsubsection{Susceptibility and coping capacity}

Susceptibility and coping capacity as components of vulnerability are defined as the degree to which a system is able or unable to cope with the adverse effects of a hazardous impact (adapted from McCarthy et al., 2001). We attempt to measure the degree of vulnerability within the specific context of tsunami early warning and evacuation: i.e. the socio-economic vulnerability assessment should provide hints on the challenges that may appear due to 


\section{Responses during the last experience}

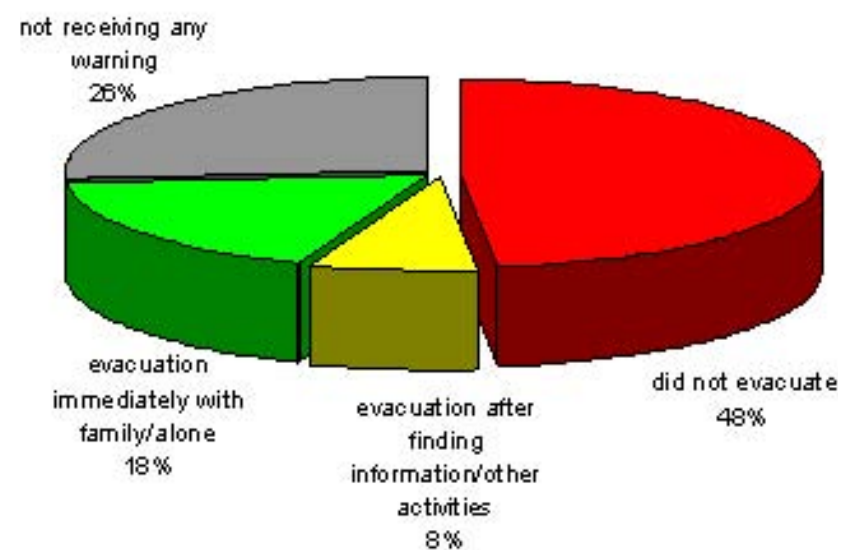

Fig. 10. Various responses to the warning during the last "potential" tsunami experience.

perception and behaviour of the people. Social groups confronted with the tsunami risk in reality indicate gaps between early warning technology and social response capability. They are not covered using pure engineering approaches or models that normally use simplified assumptions on the social aspects. It is intended to investigate parameters that would determine the susceptibility or coping capacity of various social groups during evacuation in order to understand what actually lead to the gaps identified.

Initially, the socio-economic factors influencing the exposure of various social groups to tsunamis derived from daily activity pattern and mobility data are further investigated using data obtained from the household questionnaires on socio-economic vulnerability. This provides complementary information to validate the time-specific population distribution according to the physical structural pattern extracted from remotely sensed data (cp. Sect. 4.2.1).

Subsequently, further analysis on the evacuation behaviour is conducted. As a starting point the following hypotheses were used with regard to the relevant vulnerability themes:

- various social groups have different access to early warning,

- various social groups would respond differently to the warning and to the given evacuation instruction,

- various social groups would have different capability and considerations (e.g. evacuation routes, evacuation in groups or individually) in conducting evacuation.

These hypotheses are tested using common statistical methods for descriptive analysis, correlation and regression analysis. As an example, the findings from the household questionnaires showed that during the September 2007 earthquake in the region of Padang 26.5\% of people did not receive any tsunami early warning (Fig. 10). 51.3\% received

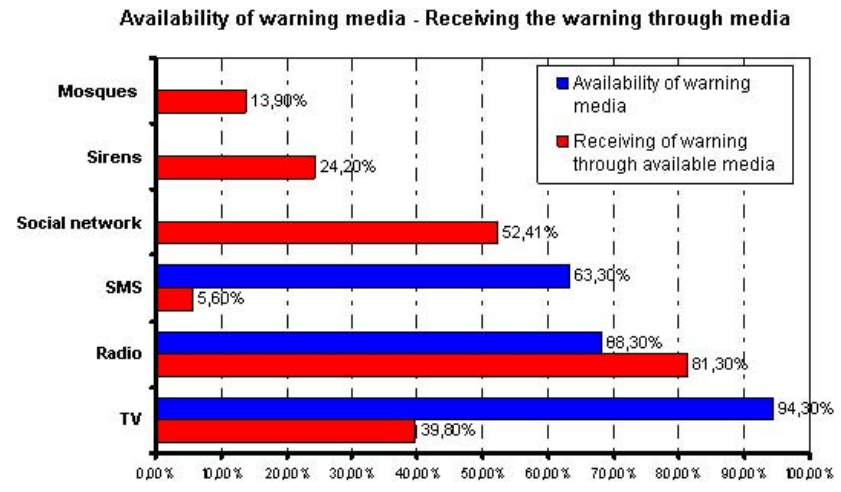

Fig. 11. Effectiveness of various media in disseminating the warning during the last experience.

formal warning through television (TV) and radio and the rest $(22.2 \%)$ were only informally notified. There was varying effectiveness of warning dissemination through different media in proportion to availability of the respective media in the households. This may be explained by the utilization of these media during the time of the event. It indicates that some households have to take uninformed decisions because of receiving different warning messages from different media. Results show that especially the informal notification and the interpretation of the warning information was difficult. There were only a small proportion of people evacuating after receiving the warning during the last experience $(34 \%)$, however, the intention for evacuating in case of future tsunami early warning showed higher rates (75\%) (Setiadi, 2008; Birkmann et al., 2008b) (cp. Figs. 11 and 12).

Multinomial logistic regressions are employed in order to investigate which parameters influence the intention to evacuate. The preliminary results identify a model of evacuation intention including parameters with some extent of significant influence, namely knowledge of tsunamis, discussion about tsunami risk in the community, perception on people's vulnerability, knowledge of evacuation places, personal preference for safe places, self-efficacy in evacuation and doubt on tsunami early warning information. The aggregation of these parameters shows the level of awareness and attitude towards the current early warning and evacuation plan and will be a proxy of potential response to tsunami early warning. Moreover, distance to the coast and household characteristics such as household size and existence of elderly also play a role.

In order to estimate the capability of the people to conduct evacuation on time, the following parameters are taken into account: particularly parameters related to demographic distribution of vulnerable groups with limited running speed (and access to vehicle, if evacuation using vehicle would be considered) as well as evacuation destination, related to evacuation knowledge, participation in evacuation drills and perceived safe places. 


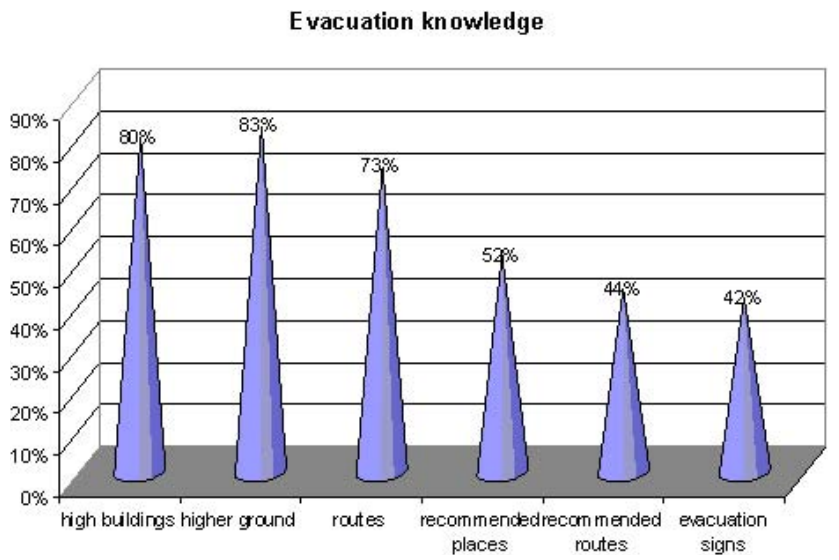

Fig. 12. Knowledge about safe places and routes of evacuation.

Such assessments reveal socio-economic parameters, which shall be used as indicators for continuous monitoring the effectiveness of implemented and planned measures - e.g. education programs - to reduce the vulnerability of the people. The assessment not solely uses questionnaires and qualitative research, but also incorporates spatial information extracted from remote sensing. This combination is an enriching approach for assessing vulnerability comprehensively.

For example the punctual household questionnaires have been investigated regarding spatial correlation to physical urban morphology. Using the physical urban morphology parameters from the city model (Fig. 8) a semantic classification has been performed. The idea of semantic classification aims at a first assumed interrelation between physically homogeneous sectors within the complex urban morphology and the socioeconomic characteristics of people residing there (Taubenböck et al., 2009). The combination of the areawide available statistical physical parameters describing the building stock of Padang per sector - built-up density, average house size, average building height, location - enables to identify physically homogeneous areas. The housing quality is assumed to be higher with rising building size or height and declining built-up density. We classify six different semantic classes - "slums", "suburbs", "low class areas" (LC), "middle class areas" (MC) and "high class areas" (HC). For every semantic class we assume typical physical conditions. As an example, slum areas are defined by the highest built-up density measured within the urban environment with mostly one storey buildings and the smallest buildings sizes.

The hypotheses that socio-economic parameters, like e.g. the income of the people, meet the assumptions made by the semantic classification are analyzed. The results show that the classified slum areas as well as the classified suburb areas reveal lowest income values independent from their location within the urban landscape. In addition consistent rising income levels to the semantic classes "low class" and

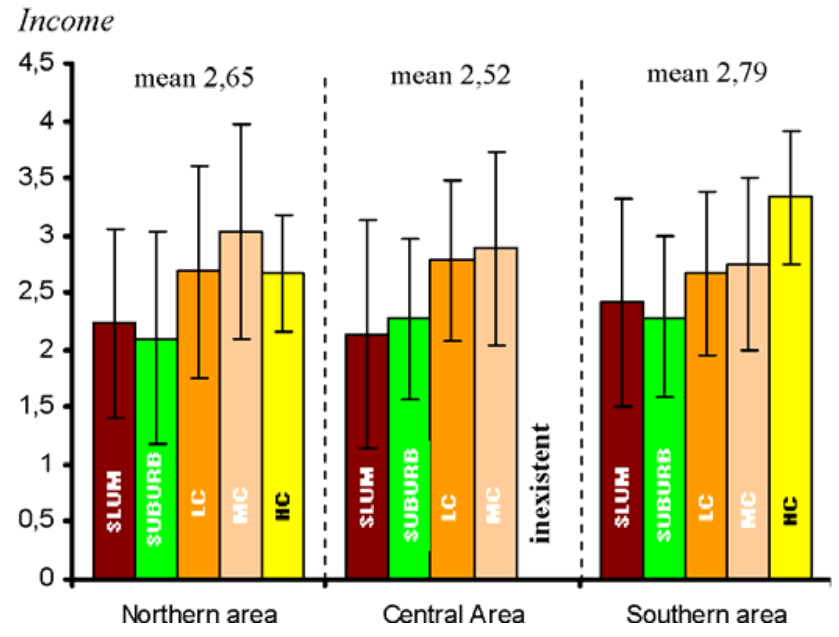

Fig. 13. Location-based mean value correlation of semantic classes derived from remotely sensed data and the socioeconomic parameter income and their standard deviation.

subsequently to "middle class" areas is found. In the southern area of Padang the observation proofs what was stated in the initial hypothesis - a rising income for the "high class", while in the northern area lower incomes for this class are detected. Thus concluding, the physical urban morphology basically correlates with socioeconomic parameters of the people. The combination of area-wide available remotely sensed data with punctual survey data shows interdisciplinary valueadding. The extrapolation enables to map spatial distribution of different social groups and thus reveals for our sample indicator "income" a spatial pattern of economic vulnerability.

The results of the assessment are also useful as inputs for deriving evacuation scenarios and simulation models, which will be further elaborated below. However, due to the fact that vulnerability assessment in the early warning context deals much with complex perception and behaviour questions, it is a great challenge to generate precise prediction on the evacuation behaviour in quantitative and probabilistic terms as well as to integrate it directly as parameters into the evacuation modeling. At the first phase, the results are generated in form of relative values for comparing different areas and social groups in the city and qualitative explanation as consideration for the potential bottlenecks.

The planning for an evacuation - after a tsunami warning is triggered - is an important aspect of disaster management. The advance warning time will be at most $30 \mathrm{~min}$. From overlapping analysis of the spatial hazard impact and assessment of dynamic population distribution approximately 230000 people are living in the affected area (Figs. 7, 9 and Table 1). Therefore, a detailed analysis of aspects that could influence the evacuation process is necessary. With this analysis it should be possible to: 
- Give an estimate of the evacuation time.

- Detect bottlenecks that could for example emerge at bridges.

- Identify highly endangered areas, where a vertical evacuation seems the only possible solution.

From these results it is planned to derive evacuation recommendations. This could include evacuation maps telling the people where to move to or recommendations where to build tsunami proof shelters. Because of the complexity of the system, an analytic solution to the evacuation problem seems impossible. Therefore a microscopic multi-agent simulation for the city with all its inhabitants has been developed. With this simulation it should be possible to obtain an estimate of the evacuation process.

There are several requirements that have to be met to get a realistic simulation. The simulation needs to reflect the socio-economic profile; this is provided by the investigation described above. Information about distribution of the population as a function of time is integrated (cp. Sect. 4.2.1), but to date, social patterns are not yet integrated in the simulations. Another important aspect for the evacuation is information about potential flooding scenarios. There is a mechanism to integrate the results from Sect. 4.1 directly in the evacuation simulation. For the physical simulation of the evacuation procedure a detailed picture of geographic structure of the city is needed. This information has mainly been extracted from satellite imagery by detecting all the walkable area in a first step and generating a network from this afterwards (cp. Sect. 4.2.1.). The network not only includes streets but also sidewalks and squares. But not all the needed information could be extracted automatically. For example it is almost impossible to detect obstacles like fences and the like from satellite images. Therefore, a survey was conducted to take geo-encoded pictures from different places where bottlenecks during evacuation could emerge. With these pictures we can estimate the accessibility of potential areas of refuge. More detailed information on the input data is given by Lämmel et al. (2009).

The evacuation simulation is based on the MATSim (multi-agent traffic simulation, www.matsim.org) framework, where each evacuee is modeled as an individual software agent. Multi-agent simulation is defined as a computational model for simulating the actions and interactions of autonomous individuals with a view to assessing their effects on the system as a whole. The underlying flow model simulates the traffic based on a simple queue model where only free speed, bottleneck capacities, and link storage capacities are taken into account. The queue simulation, albeit simple, captures the most important aspects of evacuations such as the congestion effects of bottlenecks and the time needed to evacuate the endangered area. During simulation the agents make independent decisions about escape routes or when to evacuate (i.e. their individual response times). Consequently, the evacuation for every single agent is modeled separately and is stored in a so-called plan containing the starting time and the evacuation route. A snapshot of the visualization of the simulation is shown in Fig. 14. For more technical details of the simulation framework see Lämmel et al. (2009) and Lämmel and Nagel (2009).

The results of the simulation reveal an estimation for the occurrence of bottlenecks and an estimated overall evacuation time. A major determinant for the overall evacuation time is the number and place of shelters and places of refuge. In the simulation, these are called sinks. Different from the natural places of refuge like hills, the number and places of shelter (including buildings used as shelters like concrete multi-storey buildings) can be influenced by the administration (and potentially the city's inhabitants and especially owners of buildings). Therefore, a second strategy within "Last-mile" (next to providing information and guidance on evacuation strategies) is to provide recommendations on the number and location of shelters and to identify buildings and recommend their use as shelters. A detailed anlysis of these results is given by Lämmel and Nagel (2009) and Lämmel et al. (2008).

Coping capacity in the case of a disastrous event encompasses management and physical planning, social and economic capacity. This aims at pooling all different perspectives and results along the process chain in order to derive recommendations for decision-makers before, during and after an event. The basis for substantial management is realized in a tool, where all results of the project are stored in a centralized geodatabase. The tool streams all necessary data via internet to an explicitly developed 3-D client browser with a multilingual interface. The browser enables the user, such as the city administration of Padang, rescue teams, etc. to view and analyze tsunami relevant data in 3-D at different levels of detail, even on the level of individual buildings. Because of the low data transfer rates in Indonesia's IT infrastructure, it was essential to build on very efficient multi-resolution techniques for visualizing the DSM (Wahl et al., 2004) and for efficiently mapping GIS data on it (Schneider and Klein, 2007). These techniques further improve geometry representation (Wahl et al., 2008), texturing quality (Schneider and Klein, 2008), and caching and streaming techniques in such a way that the usability and efficiency of the viewer application within a restricted network infrastructure could be assured while retaining high rendering quality. The 3-D visualization of geospatial data, adapted to the special requirements of hazard management such as tsunami events, offers an effective tool even for inexperienced GIS users to interpret geospatial data. This is indispensable if the results should be spread to a wider audience, such as stakeholder in Padang, with its limited computing and IT infrastructure. The maintenance and update of the geospatial data is very cost-efficient due to its centralized data storage.

The tool intends to improve coping capacity in manifold ways: Since it combines the interdisciplinary research results 


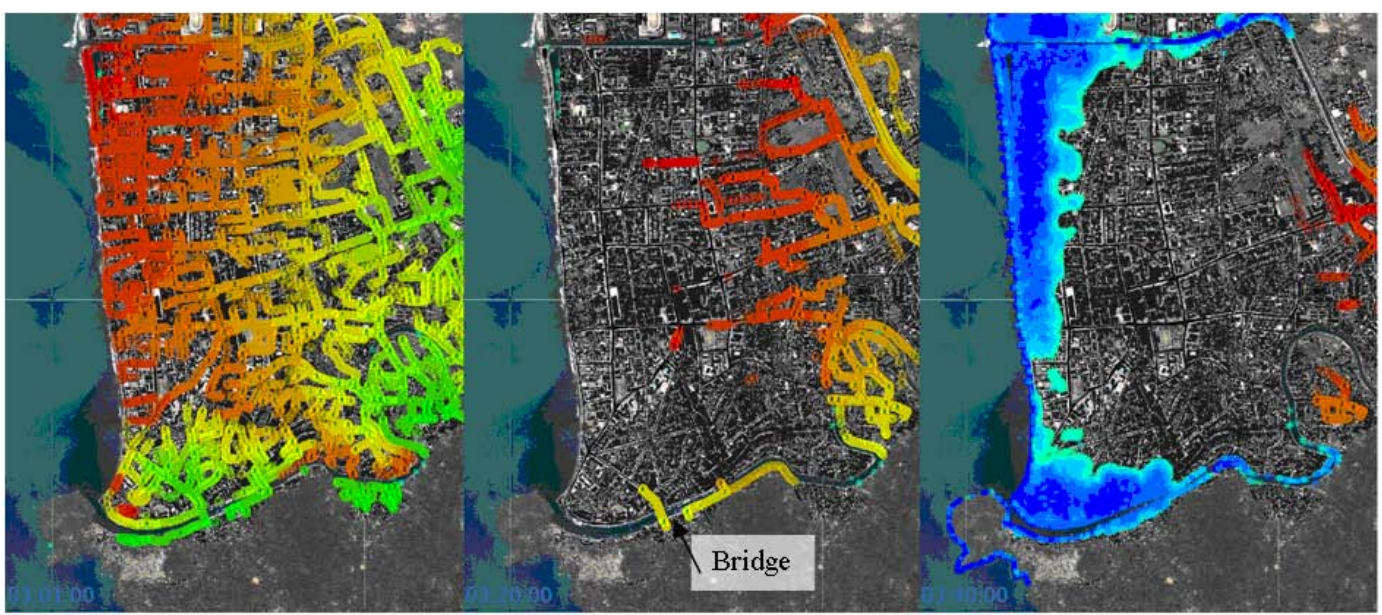

Fig. 14. Snapshots of the evacuation progress: Evacuation starts at 03:00 a.m. and the snapshots are taken after $1 \mathrm{~min}, 20 \mathrm{~min}$ and $40 \mathrm{~min}$. The agents are colorized with respect to the time they need to evacuate. The evacuation time increases as the color moves from green to yellow to red.

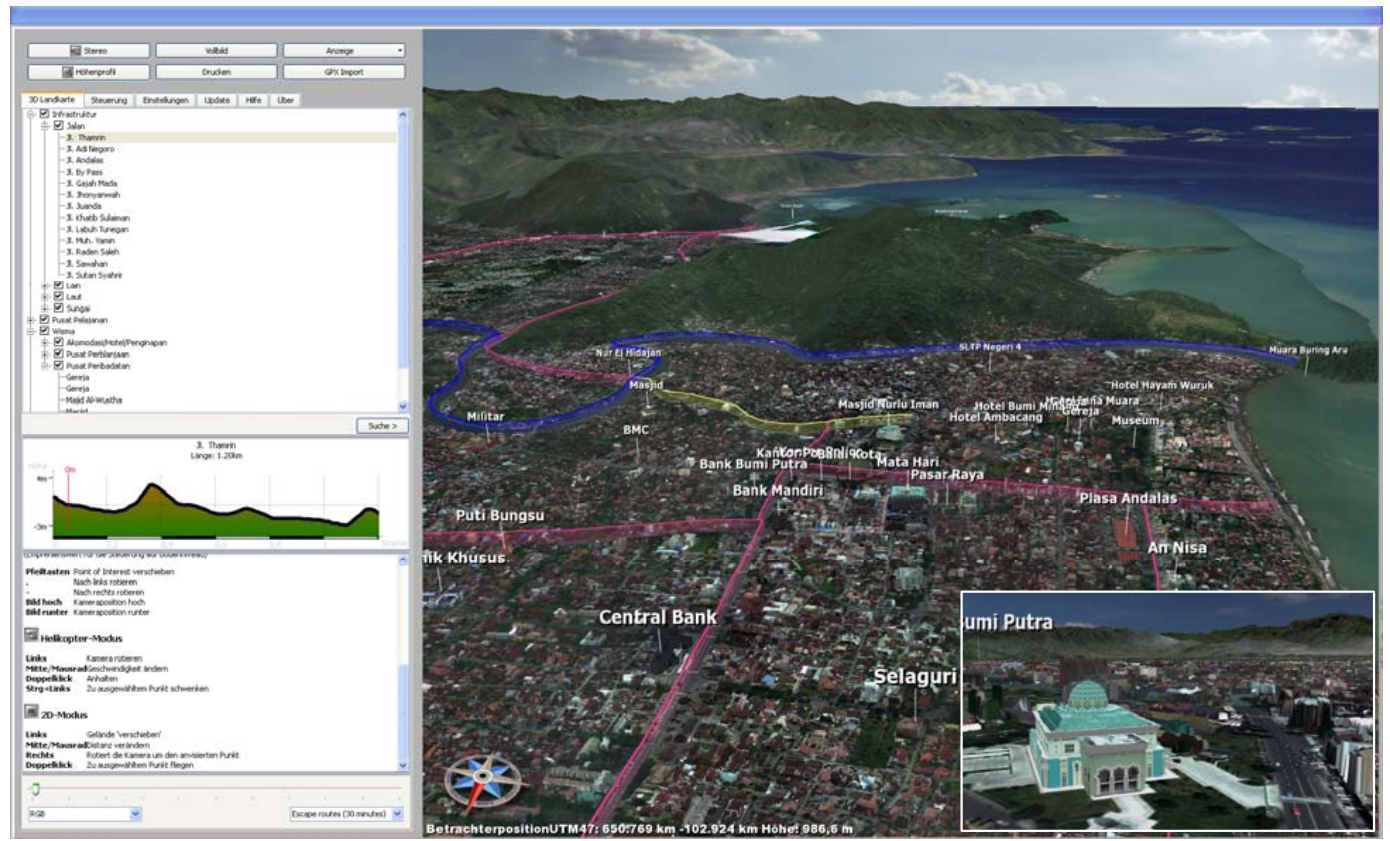

Fig. 15. Intuitive graphical user interface for data dissemination, developed by RSS in cooperation with the University of Bonn.

and visualizes them in a consistent manner (building on the concepts described in Greß and Klein, 2009), it enables to support decision making before, during and after a disastrous event. Before the event we aim at the correct assessment of various hazard scenarios to quantify exposed susceptible elements and people, assess their coping capacity and identify bottlenecks for evacuation. Furthermore the web application is used as platform for information dissemination and thus aims at awareness raising and guidance of political will. This analysis is the basis for recommendations in preparation for the expected disaster. During and after the tsunami event the platform can be used to spatially plan and manage rescue measures.

\section{Main findings and recommendations}

Overall the interdisciplinary approach results in substantial spatial information covering the hazard impact, the exposed structures, the vulnerability of elements and groups of population, and the modeling of evacuation scenarios. The 
individual disciplines depended on and benefited from spatial information from other disciplines for the particular highly detailed analysis. Furthermore the manifold results enable a holistic perspective on processes in case of a hazard event. For example, through the interdisciplinary approach of the project it is possible to develop a microscopic evacuation simulation that not only relies on highly resolved geo-spatial data but also on a detailed socio-economic profile and highly resolved small scale inundation simulations. Without such an interdisciplinary approach it would be hard to develop such an all-inclusive simulation framework. The results let us quantify the impact of potential disastrous events, and thus let us define and quantify counter-measures or relief actions needed.

The various scientific disciplines cannot perfectly map or simulate the complexity of reality. But for decision making before, during or after a disastrous event absolute accuracy is not necessary. For example remote sensing cannot accurately map cadastral data regarding population, but it can provide a fast assessment of the correct dimension of population and their whereabouts in the course of a day. Thus, the analysis is the crucial indication to identify weak points of a system as basis to develop mitigation strategies and derive recommendations.

The main findings and recommendations in our study address the questions we defined earlier in the conceptual overview (cp. Sect. 2). 1) What kind of inundation dynamics and what time frames are expected? 2) How many structures and people and which groups of people are exposed for particular hazard scenarios? 3) What factors influence different responses/behaviour to the tsunami early warning and coping capacity of various social groups in emergency situation? 4) Which bottlenecks arise during the process of evacuation? 5) Which scenario-specific decisions and recommendations have to be met to minimize disaster risk?

1. The modeling of inundation scenarios using a multiscenario approach reveal information about the affected area in the modeling domain for a given moment magnitude. The level of risk that should be addressed by disaster managers should be determined before planning activities could take place. Our approach capacitates local planers and stakeholders to decide where safe areas could be located e.g. for evacuation procedure. Information about maximum inundated areas are classified in four distinct probabilistic impact zones. Generally, zones of high risk for any earthquake triggered tsunami are distributed along the coast but also along lower parts of river mouth and channels. Highly risky zones are seriously affected by water levels and flow velocities that lead to complete damage of less robust houses. Houses and shelters in zones of medium risk will probably withstand the impact, but flow path between houses and structures will be characterized by high flow velocities that disable evacuation procedure completely. By definition, zones of low risk will be damaged least by the tsunami impact and the timeframe of inundation dynamics will allow for the longest possible evacuation progress. Since all results are still snapshots of workin-progress, only qualitative statements could be given at this stage, but we refer the reader to prospective publications by the authors for quantitative conclusions and details.

2. The combination of the spatial impact of the potential tsunami with the urban structures derived from remotely sensed data sets enables quantification of affected structures, their types and their location. Exemplary 37347 structures were identified and localized in different risk zones of the hazard map. Furthermore, the land-cover classification enables to identify and localize natural safe areas, defined as open spaces accessible by the street network larger than $10.000 \mathrm{~m}^{2}$ to be able to accommodate enough people in a rescue situation. Furthermore the area must be flat with land-cover bare soil or grassland and with respect to the hazard map a location outside any inundation area. The indirect derivation of dynamic population distribution with respect to the time of day results in the assessment of potentially affected people and their location. Exemplary the overlapping analysis of the spatial hazard scenario with the 3 -D city model and the population assessment resulted in 227000 people at daytime and 217000 at night-time. The socioeconomic analysis using the questionnaire reveals the susceptibility and coping capacity of various groups and their locations.

3. Socio-economic vulnerability assessment through questionnaire-based surveying and additional qualitative studies on the specific themes such as access to the warning and the potential response or behaviour of the people reveal the social bottlenecks to be considered when establishing a people-centred effective early warning and evacuation planning. It provides better understanding on how the people adapt to the current risk reduction measures and what kind of additional measures are necessary. Spatial assessment of the socio-economic parameters such as income, and other related parameters enables projection of distribution of various social groups in the city areas as well as to generate thematic maps on vulnerability. Furthermore the usage of different media to warn people, e.g. TV, radio or sirens, clearly results in an increase of reached people, and thus becomes a recommendation to be developed further for warning dissemination. The results also clearly reveal that education programs should focus on recommended evacuation routes.

4. Basically evacuation by foot is recommended due to heavy traffic jam situation in the last warning situation in 2007. From the pre-calculated evacuation simulation 
it is possible to detect potential bottlenecks in advance and give scenario specific evacuation recommendations. For example the bridge indicated in Fig. 14 is identified as bottleneck with a too low capacity for the accumulating evacuees. In the case of the estimated minimum tsunami arrival time of $23 \mathrm{~min}$ a highly vulnerable spatial area is localized. Furthermore, one gets information about estimated evacuation times on a geographic highly resolved level. As shown in the example of Fig. 14 only after $40 \mathrm{~min}$ almost the entire population was evacuated from potentially inundated areas from the sample tsunami scenario. From this assessment, areas where a vertical evacuation seems to be the only possible solution have to be localized. With the flexibility of MATSim it will be possible to simulate different scenarios regarding the distribution of the population, the inundation and the location of tsunami proof shelters. Therefore it will be possible to adapt the simulation if some parameters of the city change (e.g. widening of narrow streets, building of new bridges or the like).

5. The combination of the various aspects in the early warning chain enables to identify numerous recommendations and strategies for awareness raising, warning dissemination or spatial planning: The socioeconomic analysis reveals that awareness of the people and household characteristics have influence on the evacuation behaviour. The correlation with remotely sensed data even lets us localize extremely susceptible groups of people. Thus, we recommend standardized and locationspecific education for the people, in order to make them aware on what to do in case of potential tsunami situation and provision of an early warning; it is also important to provide clear information to the people on where the recommended places and routes to evacuate are. Due to very short time availability to conduct evacuation and limitation of various available media, it is also recommended to empower the people to disseminate the warning in an "organized" informal way, such as through neighbourhood leaders or trained community teams.

The evacuation simulation reveals bottlenecks - mainly at bridges - giving manifold further options for improving the coping capacity. We identified safe areas and recommend to signpost them and with it to manage and thus release congestion areas in case of evacuation. If the overall evacuation time for the situation as it is exceeds an agreed maximum time (i.e., acceptance criterion), one possible strategy is to place shelters at locations identified on the basis of simulation results. We also recommend improving accessibility of the two natural elevation areas within the urban area of Padang as additional vertical shelter areas. Next to bottlenecks, the walking distance to a place of refuge is the second major determinant for the overall evacuation time. Addi- tional shelters will reduce this walking distance for persons living or working close to those shelters. This will reduce the overall evacuation time, if for certain scenarios the individual evacuation time for many evacuees is modelled as "too large" (i.e., higher than the accepted time). Therefore, this seems to be a very promising strategy. The success of this strategy can be quantified by performing a simulation with taking the shelters into account.

\section{Summary and outlook}

The Last-Mile preparation for an expected natural disaster is an ongoing research project. The products developed are disseminated to local stakeholders, decision-makers and officials. Results serve as one essential information basis on how to proceed with governance regarding hazard assessment, disaster mitigation, strategic planning and the formulation of policies on land use planning to reduce the potential impact of a tsunami at the city of Padang.

Future analysis will focus on tsunami impact assessment utilizing vulnerability models of structures. Therefore the interdisciplinary research combining civil engineering and remote sensing aims to correlate punctual survey data with the area-wide physical parameters of the individual building for extrapolation on the complete building stock of Padang. Thus, stable structures for vertical evacuation will be identified. The integration of tsunami proof shelters will be an important aspect regarding the evacuation simulation framework. Therewith, it will be possible to find appropriate locations for those shelters and one could even assign shelters to the people subjected to their whereabouts.

Interaction between social and engineering sciences presented in this study offers a more comprehensive manner of the analysis and consequently a more applied product. Additional disciplines or common efforts to establish more intensive participation of the local stakeholders may be necessary, especially in adjusting the format of the information system to fit the local capacity and local planning purposes. This would ensure the acceptance and sustainable application of the scientific product.

In addition it is planned to visualize simulation results in high resolution video clips, showing evacuation routes and other relevant information for education and awareness purposes. 3-D Studio Max will be used to render the video sequences. Wave simulation, evacuation routes and points, as well as instructions on behavior, are shown in the video sequences and will be used for awareness campaigns and training units. The video sequences are designed to allow recognition of the city environment by using the 3-D city model textured with the building façade photos. In summary, the multifaceted interdisciplinary results within the "LastMile" project aim to holistically assess risk and vulnerability to mitigate human losses in case of the expected tsunami event. 
Acknowledgements. The authors would like to thank the DFG/BMBF special Programme "Geotechnologies" - Early Warning Systems in Earth Management. Sponsorship Code: 03G0666A-E. We would also like to thank our partners from Andalas University as well as the provincial and city authorities in the city of Padang, West Sumatra, Indonesia. We would also like to thank the Alfred-Wegener-Institute (AWI) for provision of deep-water propagation studies.

Edited by: S. Tinti

Reviewed by: three anonymous referees

\section{References}

Barber, B.: Tsunami relief, US Agency for International Development, Washington DC, 28 pp., 2005.

Behrens, J.: TsunAWI - Unstructured Mesh Finite Element Model for the Computation of Tsunami Scenarios with Inundation, Proceedings of NAFEMS Seminar, 2008.

Bernard, E. N., Mofjeld, H. O., Titov, V., Synolakis, C. E., and Gonzalez, F. I.: Tsunami: Scientific frontiers, mitigation, forecasting and policy implications, Philos. T. R. Soc. A, 364, 1989-2007, 2006.

Bernhard, E.: The U. S. National Tsunami Hazard Mitigation Program: A Successful State-Federal Partnership, Nat. Hazards, 35, 5-24, 2005.

Bierlaire, M., Antonini, G., and Weber, M.: Behavioral dynamics for pedestrians, in: Moving through nets: The physical and social dimensions of travel, edited by: Axhausen, K., Elsevier, 2003.

Birkmann, J.: Measuring vulnerability to promote disaster-resilient societies: Conceptual frameworks and definitions, in: Measuring Vulnerability to Natural hazards - Towards Disaster Resilient Societies, edited by: Birkmann, J., New York, United Nations University, 9-54, 2006.

Birkmann, J., Dech, S., Goseberg, N., Lämmel, G., Moder, F., Nagel, K., Oczipka, M., Schlurmann, T., Setiadi, N., Siegert, F., Strunz, G. and Taubenböck, H.: Numerical Last-Mile Tsunami Early Warning and Evacuation Information System, in: International Conference on Tsunami Warning (ICTW), Bali, Indonesia, 12 pp., 12-14 November 2008a.

Birkmann, J., Setiadi, N., and Gebert, N.: Socio-economic vulnerability assessment at the local level in context of tsunami early warning and Evacuation planning in the city of Padang, West Sumatra, Paper for International Conference on Tsunami Warning, Nusa Dua, Indonesia, 12-14 November 2008b.

Blaikie, P., Cannon, T., Davis, I., and Wisner, B.: At Risk: Natural Hazards, People's Vulnerability and Disasters, Routeledge, London, S. 320, 1994.

Bogardi, J. and Birkmann, J.: Vulnerability Assessment: The First Step Towards Sustainable Risk Reduction, in: Disaster and Society - From Hazard Assessment to Risk Reduction, edited by: Malzahn, D. and Plapp, T., Logos Verlag Berlin, Berlin, 75-82, 2004.

Börner, A., Hirschmüller, H., Scheibe, K., Suppa, M., and Wohlfeil, J.: MFC - a modular line camera for 3D world modeling in Lecture Notes, in: Computer Science, Berlin/Heidelberg, Germany, January 2008.

Borrero, J. C., Sieh, K., Chlieh, M., and Synolakis, C. E.: Tsunami inundation modeling for western Sumatra, P. Natl. Acad. Sci.
USA, 103, 19673-19677, available at: http://www.pnas.org, 2006.

Borrero, J. C., Bourgeois, J., Harkins, G., and Synolakis, C. E.: How small-scale bathymetry affected coastal inundation in the 1992 Nicaraguan tsunami, Proc. of the Fall AGU Meeting, San Francisco, 1997.

Burbridge, D., Cummins, P. R., Mleczko, R., and Thio, H. K.: A Probabilistic Tsunami Hazard Assessment for Western Australia, Pure Appl. Geophys., 165(11-12), 2059-2088(30), 2008.

Cannon, T., Twigg, J., and Rowell, J.: Social Vulnerability: Sustainable Livelihoods and Disasters, Report to DFID Conflict and Humanitarian Assistance Department (CHAD) and Sustainable Livelihoods Support Office, http://www.proventionconsortium. org/themes/default/pdfs/CRA/DFIDSocialvulnerability.pdf, 2003.

Cardona, O. D.: Environmental Management and Disaster Prevention: Two Related Topics: A Holistic Risk Assessment and Management Approach, in: Natural Disaster Management, edited by: Ingleton, J., Tudor Rose, London, 1999.

Cardona, O. D.: Estimación Holistica del Riesgo Sismico Utilizando Sistemas Dinámicos Complejos, Technical University of Catalonia, Barcelona, http://www.desenredando.org/public/ varios/2001/ehrisusd/index.html, 2001

Chen, X. and Zhan, F.: Agent-based modeling and simulation of urban evacuation: Relative effectiveness of simultaneous and staged evacuation strategies. Paper 04-0329, Transportation Research Board Annual Meeting, Washington, DC, 2004.

Correll, R., Cramer, W., and Schellnhuber, H.-J.: Potsdam sustainability days, Symposium on "Methods and Models of Vulnerability Research, Analysis and Assessment”, 2001.

Davidson, R.: An Urban Earthquake Disaster Risk Index, The John A. Blume Earthquake Engineering Center, Department of Civil Engineering, Stanford University, Stanford, Report No. 121, 1997.

Goseberg, N., Stahlmann, A., Schimmels, S., and Schlurmann, T.: Highly-resolved numerical modeling of tsunami run-up and inundation scenario in the city of Padang, West Sumatra, Proc. of the 31st Int. Conference on Coastal Engineering, in press, 2009.

Goseberg, N. and Schlurmann, T.: Relevant factors on the extent of inundation Based on Tsunami scenarios for the city of Padang, West Sumatra, Proc. of the International Conference on Tsunami Warning (ICTW), 2008.

Goto, C., Ogawa, Y., Shuto, N., and Imamura, N.: IOC Manual, UNESCO, No. 35, 1997.

Greß, A. and Klein, R.: Visualization Framework for the Integration and Exploration of Heterogeneous Geospatial Data, Proceedings of Eurographics 2009 - Areas Papers, Eurographics Association, 27-34, April 2009.

Harig, S., Chaeroni, C., Behrens, J., and Schroeter, J.: Tsunami Simulations with unstructured grids (TsunAWI) and a comparison to simulations with nested grids (Tsunami-N3), 6th Int. Workshop on Unstructured Mesh Numerical Modeling of Coastal, Shelf and Ocean Flows, London, 2007.

Helbing, D., Farkas, I., and Molnar, P.: Simulation of pedestrian crowds in normal and evacuation situations, in: Pedestrian and Evacation Dynamics, Proceedings of the 1st international conference, Duisburg, 2001, Springer, 2002.

Hobeika, A. and Kim, C.: Comparison of traffic assignments in evacuation modeling, IEEE T. Eng. Manage., 45(2), 192-198, 
1998.

Intermap Technologies: Product Handbook \& Quick Start Guide, Standard Edition, v4.0, 2007.

IPCC: Climate Change 2001: Impacts, Adaption, and Vulnerability, Published for the Intergovernmental Panel on Climate Change, University Press, Cambridge, ISBN 0-521-80768-9, 2001.

Jha, M., Moore, K., and Pashaie, B.: Emergency evacuation planning with microscopic traffic simulation, Transportation Research Board Annual Meeting, Washington, DC, Paper 04-2414, 2004.

Kass, S., Post, J., Taubenböck, H., Roth, A., Strunz, G., Stötter, J., Mardiatno, D., Ismail, F., and Anwar, H.: Automated assessment of building vulnerability with high resolution IKONOS data for Padang, Indonesia, Proceedings of the International Symposium on Disaster in Indonesia: Problems and Solutions, Padang, July 2007.

Klüpfel, H., Meyer-König, T., Keßel, A., et al.: Simulating evacuation processes and comparison to empirical results, in: Traffic and granular flow '01, edited by: Fukui, M., Sugiyama, Y., Schreckenberg, M., and Wolf, D., Springer, Berlin/Heidelberg/New York, 449-454, 2003.

Kwon, E. and Pitt, S.: Evaluation of emergency evacuation strategies for downtown event traffic using a dynamic network model, Transportation Research Board Annual Meeting, Washington, DC, Paper 05-2164, 2005.

Lämmel, L., Rieser, M., and Nagel, K.: Large Scale Microscopic Evacuation Simulation, Proc. 4th International Conference on Pedestrian and Evacuation Dynamics, Wuppertal, Germany, in press, 2009.

Lämmel, L., Rieser, M., Nagel, K., Taubenböck, H., Strunz, G., Goseberg, N., Schlurmann, T., Klüpfel, H., Setiadi, N., and Birkmann, J.: Emergency Preparedness in the case of a Tsunami Evacuation Analysis and Traffic Optimization for the Indonesian city of Padang, Proc. of the 4th Interantional Conference on Pedestrian and Evacuation Dynamics, Wuppertal, Germany, 2008.

Lämmel, L. and Nagel, K.: Multi agent based large-scale evacuation simulation, Transportation Research Board Annual Meeting, Washington, DC, Paper 09-2135, 2009.

Lämmel, L., Klüpfel, H., and Nagel, K.: Preliminary Result of a Large Scale Microscopic Evacuation Simulation for the City of Padang in the Case of Tsunami, Proc. of the International Conference on Tsunami Warning (ICTW), Bali, Indonesia, http://pirba.ristek.go.id/ictw/e-proceedings/PDF/4.\%20ICW/ ICW05DE\%20Laemmel\%20Gregor.pdf, 2008.

Last-Mile Project: www.last-mile-evacuation.de, 2009.

Lauterjung, J. and Rudloff, A.: GITEWS - The German Indonesian Tsunami Early Warning System, EOS T. Am. Geophys. Un., 86(52), Fall Meet. Suppl., 2005.

Leitmann, J.: Cities and Calamities: Learning from Post-Disaster response in Indonesia, in: Journal of Urban Health: Bulletin of the New York Academy of Medicine, 84(1), 144-153(10), 2007.

Leone, F., Denain, J.-C., Vinet, F., and Bachri, S.: Analyse spatiale des dommages au bâti d Banda Aceh (Sumatra, Indonésie): contribution à la connaissance du phénomène et à l'élaboration de scénarios de risque tsunami, in: Le tsunami du 26 décembre 2004 en Indonésie - Rapport scientifique du programme TSUNARISQUE (2005-2006), 69-94, edited by: Lavigne, F. and Paris, R., Délégation Interministérielle pour l'aide
Post-Tsunami (DIPT), Ambassade de France en Indonésie, Centre National de la Recherche Scientifique, 356 pp., 2007.

Lynett, P., Wu, T.-R., and Liu, L.-F.: Modeling wave runup with depth-integrated equations, Coast. Eng., 46, 89-107, 2002.

Marschalk, U., Roth, A., Eineder, M., and Suchandt, S.: Comparison of DEMs derived from SRTM/X- and C-Band, in: Proceedings of the IGARSS 2004, Anchorage, USA, 2004.

McCarthy, J. J., Canziani, O. F., Leary, N. A., Dokken, D. J., and White, K. S. (Eds.): Climate Change: Impacts, Adaptation and Vulnerability, Cambridge University Press, Cambridge, 2001.

McCloskey, J., Antonioli, A., Piatanesi, A., Sieh, K., Steacy, S., Nalbant, S., Cocco, M., Giunchi, C., Huang, J. and Dunlop, P.: Tsunami threat in the Indian Ocean from a future megathrust earthquake west of Sumatra, Earth Planet. Sc. Lett., 265, 61-81, 2008.

Moder, F., Oczipka, M., Siegert, F., Lehmann, F., Djajadihardaja, Y. S., Klein, R., and Wahl, R.: Last-Mile - Large-Scale topographic mapping of densely populated coasts in support of risk assessment of tsunami hazards, International Conference on Tsunami Warning, Bali, Indonesia, 12-14 November 2008.

Nielsen, O., Roberts, S., Gray, D., McPherson, A., and Hitchman, A.: Hydrodynamic modeling of coastal Inundation, in: MODSIM 2005 Int. Congress on Modeling and Simulation, Zerger, A. (Hrsg.), Modeling and Simulation Society of Australia and New Zealand, 518-523, 2005.

Papathoma, M., Dominey-Howes, D., Zong, Y., and Smith, D.: Assessing tsunami vulnerability, an example from Herakleio, Crete, Nat. Hazards Earth Syst. Sci., 3, 377-389, 2003, http://www.nat-hazards-earth-syst-sci.net/3/377/2003/.

Pedersen, G., Liu, P. L., Yeh, H., and Synolakis, C.: Advanced numerical models for simulating tsunami waves and runup, World Scientific, 10 pp., 2008.

Peeta, S. and Ziliaskopoulos, A.: Foundations of Dynamic Traffic Assignment: The Past, the Present and the Future, Netw. Spat. Econ., 1(3), 233-265, 2001.

Rastogi, B. K. and Jaiswal, R. K.: A Catalogue of Tsunamis in the Indian Ocean, Science of Tsunami Hazards, 25(3), 128-143, 2006.

Reese, S., Cousins, W. J., Power, W. L., Palmer, N. G., Tejakusuma, I. G., and Nugrahadi, S.: Tsunami vulnerability of buildings and people in South Java field observations after the July 2006 Java tsunami, Nat. Hazards Earth Syst. Sci., 7, 573-589, 2007, http://www.nat-hazards-earth-syst-sci.net/7/573/2007/.

Richter, R.: A spatially adaptive fast atmospheric correction algorithm, Int. J. Remote Sens., 17(6), S. 1201-1214, 1996.

Saita, J. and Nakamura, Y.: UrEDAS: The Early Warning System for Mitigation of Disasters Caused by Earthquakes and Tsunamis, in: Early Warning Systems for Natural Disaster Reduction, edited by: Zschau, J. and Küppers, N., Springer, 2003.

Schneider, M. and Klein, R.: Enhancing Textured Digital Elevation Models Using Photographs. Proceedings of the Fourth International Symposium on 3D Data Processing, Visualization and Transmission (3DPVT'08), 2008.

Schneider, M. and Klein, R.: Efficient and Accurate Rendering of Vector Data on Virtual Landscapes, Journal of WSCG, 15(1-3), 59-64, January 2007.

Schneiderbauer, S. and Ehrlich, D.: Risk, Hazard and People's Vulnerability to Natural Hazards: A Review of Definitions, Concepts and Data, European Commission-Joint Research Centre 
(EC-JRC), Brussels, 2004.

Schneiderbauer, S. and Ehrlich, D.: Social levels and hazard (in)dependence in determining vulnerability, in: Measuring Vulnerability to Natural hazards - Towards Disaster Resilient Societies, edited by: Birkmann, J., New York, United Nations University, 78-98, 2006.

Setiadi, N.: WP 1000: Socio-Economic Vulnerability Assessment - Numerical Last-Mile Tsunami Early Warning and Evacuation System, Presentation for the Status Meeting Geotechnologies, Osnabrück, 8 October 2008.

Sheffi, Y.: Urban Transportation Networks: Equilibrium Analysis with Mathematical Programming Methods, Prentice-Hall, Englewood Cliffs, NJ, USA, 1985.

Sorensen, J. H.: Hazard Warning Systems: Review of 20 Years of Progress, Natural Hazards Review, 1, 119-125, 2000.

Synolakis, C. E. and Bernard, E. N.: Tsunami science before and beyond Boxing Day 2004, Philos. T. R. Soc. A, 364, 2231-2265, 2006.

Taubenböck, H. and Roth, A.: A transferable and stable classification approach in various urban areas and various high resolution sensors, Proc. of the Urban Remote Sensing Joint Event, Paris, France, S. 7, 2007.

Taubenböck, H., Roth, A., and Dech, S.: Linking structural urban characteristics derived from high resolution satellite data to population distribution, in: Urban and Regional Data Management, Coors, Rumor, Fendel and Zlatanova (Hrsg.), Taylor \& Francis Group, London, ISBN 978-0-41544059-2, S. 35-45, 2007.

Taubenböck, H., Post, J., Roth, A., Zosseder, K., Strunz, G., and Dech, S.: A conceptual vulnerability and risk framework as outline to identify capabilities of remote sensing, Nat. Hazards Earth Syst. Sci., 8, 409-420, 2008a, http://www.nat-hazards-earth-syst-sci.net/8/409/2008/.

Taubenböck, H., Post, J., Kiefl, R., Roth, A., Ismail, F., Strunz, G., and Dech, S.: Risk and vulnerability assessment to tsunami hazard using very high resolution satellite data, in: Proceedings of the EARSeL Joint Workshop: Remote Sensing: New Challenges of high resolution, edited by: Carsten, J., Bochum, Germany, ISBN 978-3-925143-79-3, 77-86, http://www.earsel.org/ workshops/HighRes2008/Artikel/09_Taubenboeck.pdf, 2008b.

Taubenböck, H., Post, J., Roth, A., Strunz, G., Kiefl, R., Dech, S., and Ismail, F.: Multi-scale assessment of population distribution utilizing remotely sensed data - The case study Padang, West Sumatra, Indonesia, International Conference on Tsunami Warning (ICTW), Bali, Indonesia, 12-14 November 2008c.
Taubenböck, H., Wurm, M., Setiadi, N., Gebert, N., Roth, A., Strunz, G., Birkmann, J., and Dech, S.: Integrating Remote Sensing and Social Science - The correlation of urban morphology with socioeconomic parameters, Urban Remote Sensing Joint Event, Shanghai, China, 2009.

Tinti, S., Manucci, A., Pagnoni, G., Armigliato, A., and Zaniboni, F.: The 30 December 2002 landslide-induced tsunamis in Stromboli: sequence of the events reconstructed from the eyewitness accounts, Nat. Hazards Earth Syst. Sci., 5, 763-775, 2005, http://www.nat-hazards-earth-syst-sci.net/5/763/2005/.

Titov, V., Gonzalez, F., Bernhard, E., Eble, M., Mofjeld, H., Newman, J., and Venturato, A.: Real-time tsunami forecasting: Challenges and solutions, Nat. Hazards, 35, 41-58, 2005.

Titov, V. V. and Synolakis, C. E.: Numerical modeling of tidal wave runup, J. Waterway Div.-ASCE, 124, 157-171, 1998.

Turner, B. L., Kasperson, R. E., Matson, P. A., McCarthy, J. J., Corell, R. W., Christensen, L., Eckley, N., Kasperson, J. X., Luers, A., Martello, M. L., Polsky, C., Pulsipher, A., and Schiller, A.: A framework for vulnerability analysis in sustainability science, P. Natl. Acad. Sci. USA, 100(14), 8074-8079, 2003.

United Nations International Strategy for Disaster Reduction (UN/ISDR): Living with Risk: A global Review of Disaster Reduction Initiatives, United Nations International Strategy for Disaster Reduction, Geneva, Switzerland, UN Publications, 2004.

United Nations International Strategy for Disaster Reduction (UN/ISDR): Global Survey of Early Warning Systems, UN/ISDR, ISDR/PPEW, 2006.

Wahl, R., Schnabel, R., and Klein, R.: From Detailed Digital Surface Models to City Models Using Constrained Simplification, Photogramm. Fernerkun., 3, 207-215, 2008

Wahl, R., Massing, M., Degener, P., Guthe, M., and Klein, R.: Scalable Compression and Rendering of Textured Terrain Data, Journal of WSCG, 12(3), 521-528, February 2004.

Zoppou, C. and Roberts, S.: Catastrophic Collapse of Water Supply Reservoirs in Urban Areas, J. Hydraul. Eng.-ASCE, 125, S. 686695, 1999. 